\title{
The Molecular Basis for Specificity at the Level of the Protein Kinase a Catalytic Subunit
}

\author{
Kristoffer Søberg ${ }^{1}$ and Bjørn Steen Skålhegg ${ }^{2 *}$ \\ ${ }^{1}$ Department of Medical Genetics, Oslo University Hospital, Oslo, Norway, ${ }^{2}$ Section for Molecular Nutrition, University of \\ Oslo, Oslo, Norway
}

Assembly of multi enzyme complexes at subcellular localizations by anchoring- and scaffolding proteins represents a pivotal mechanism for achieving spatiotemporal regulation of cellular signaling after hormone receptor targeting [for review, see (1)]. In the 3' 5'-cyclic adenosine monophosphate (CAMP) dependent protein kinase (PKA) signaling pathway it is generally accepted that specificity is secured at several levels. This includes at the first level stimulation of receptors coupled to heterotrimeric $G$ proteins which through stimulation of adenylyl cyclase (AC) forms the second messenger CAMP. Cyclic AMP has several receptors including PKA. PKA is a tetrameric holoenzyme consisting

OPEN ACCESS

Edited by:

Pierre De Meyts,

de Duve Institute, Belgium

Reviewed by:

Enzo Lalli,

UMR7275 Institut de Pharmacologie Moléculaire et Cellulaire (IPMC)

France

Mariusz W. Szkudlinski,

Trophogen, United States

*Correspondence:

Bjørn Steen Skålhegg

b.s.skalhegg@medisin.uio.no

Specialty section:

This article was submitted to

Molecular and Structural Endocrinology,

a section of the journal

Frontiers in Endocrinology

Received: 22 June 2018

Accepted: 24 August 2018

Published: 12 September 2018

Citation:

Søberg K and Skålhegg BS (2018) The Molecular Basis for Specificity at the Level of the Protein Kinase a Catalytic Subunit.

Front. Endocrinol. 9:538.

doi: 10.3389/fendo.2018.00538 of a regulatory $(R)$ subunit dimer and two catalytic $(C)$ subunits. The $R$ subunit is the receptor for CAMP and compartmentalizes cAMP signals through binding to cell and tissue-specifically expressed A kinase anchoring proteins (AKAPs). The current dogma tells that in the presence of cAMP, PKA dissociates into an R subunit dimer and two $\mathrm{C}$ subunits which are free to phosphorylate relevant substrates in the cytosol and nucleus. The release of the $\mathrm{C}$ subunit has raised the question how specificity of the cAMP and PKA signaling pathway is maintained when the $C$ subunit no longer is attached to the $\mathrm{R}$ subunit-AKAP complex. An increasing body of evidence points toward a regulatory role of the cAMP and PKA signaling pathway by targeting the $C$ subunits to various $C$ subunit binding proteins in the cytosol and nucleus. Moreover, recent identification of isoform specific amino acid sequences, motifs and three dimensional structures have together provided new insight into how PKA at the level of the $\mathrm{C}$ subunit may act in a highly isoform-specific fashion. Here we discuss recent understanding of specificity of the CAMP and PKA signaling pathway based on C subunit subcellular targeting as well as evolution of the $\mathrm{C}$ subunit structure that may contribute to the dynamic regulation of C subunit activity.

Keywords: PKA, anchoring, catalytic subunit, specificity, molecular determinants

\section{THE CAMP AND PKA SIGNALING PATHWAY AND CAMP RECEPTORS}

In the classical conception of the Protein kinase A (PKA) signaling pathway, depicted in Figure 1, activation of PKA starts with the binding of a ligand to a seven transmembrane G protein coupled receptor [GPCR, denoted (1) in Figure 1]. Examples of such ligands include the hormones epinephrine, prostaglandin E2 (PGE2) and glucagon in addition to various neurotransmitters and 
other signal substances $(3,4)$. GPCRs have an extracellular surface recognizing ligands, and an intracellular surface interacting with membrane-bound heterotrimeric $G$ proteins [denoted (2)]. Binding of a ligand to the extracellular part causes a conformational change in the $G$ protein-interacting surface of the GPCR. The heterotrimeric G proteins are composed of $\alpha, \beta$, and $\gamma$ subunits. In the inactive state, all subunits are bound together, and the $\alpha$ subunit has a GDP-molecule attached. After activation through the ligand-bound GPCR, the $\alpha$ subunit exchanges its GDP-molecule with GTP [denoted (3)]. This causes dissociation of the subunits into an activated $\alpha$ subunit and an activated $\beta \gamma$ complex $(5,6)$. There are several types of $G$ protein $\alpha$ subunits $(G \alpha)$, and different $\alpha$ subunits show distinct specificities. In the PKA signaling pathway, the stimulatory $G$ protein known as $\mathrm{GS}_{\mathrm{S}}$ activates membrane (m)-bound adenylyl cyclase [AC, denoted (4)] (7).The mACs produce cAMP from ATP, and can increase the intracellular cAMP-concentration by more than twentyfold in seconds after stimulation (8). Free cAMP [denoted (5)] can bind to and stimulate several proteins, including popeye domain-containing [POPDC, denoted (6)] proteins, cyclic nucleotide-gated ion channels [CNGs, denoted (7)], exchange protein directly activated by cAMP [Epac, denoted (8)], and PKA holoenzymes [denoted (9)] $(3,4)$. CNGs are identified in photoreceptor cells, olfactory sensory neurons, cardiac sinoatrial node cells, kidney, liver, lymphocytes, muscle, and testis (9-13). CNG channels in visual and olfactory sensory cells convert stimuli into electrical signals through cationic influx, mainly $\mathrm{Ca}^{2+}$ (14). Cyclic AMP binds to Epac with high affinity and activates the Ras superfamily of small GTPases Rap1 and Rap2 (15). There are two variants of mammalian Epac, Epac1, and Epac2. Epac is involved in a range of processes, including cell adhesion, cell-cell junction, exocytosis/secretion, cell differentiation and proliferation, gene expression, apoptosis, cardiac hypertrophy, and phagocytosis (15-17). POPDC proteins are a family of membrane proteins that are found in cardiac and skeletal muscle cells, among other tissues, and are encoded by the three genes POPDC1, $P O P D C 2$, and POPDC3. They have high affinities to cAMP, and mutations in the POPDC1 gene have been implicated in limb-girdle muscular dystrophy and cardiac arrhythmia $(18,19)$. Despite a vast number of reports describing these receptors for cAMP, the best studied cAMP receptor is PKA [denoted (9) in Figure 1] (3). Inactive PKA exists as a tetrameric holoenzyme of two regulatory $(\mathrm{R})$ subunits in a dimer formation and two catalytic $(\mathrm{C})$ subunits. The $\mathrm{R}$ subunits contain two cAMP binding domains (CBDs, A and B) each. Binding of cAMP to CBD B causes a conformational change of the $\mathrm{R}$ subunits and exposure of CBD A. The classical conception of two cAMP molecules bound to each of the $\mathrm{R}$ subunits is that the $\mathrm{C}$ subunits are released and in that way become catalytically active (20). The C subunits belong to the serine threonine protein kinase (STKs) family of enzymes, and more than 250 PKA-substrates are identified (21). The consequences of PKA activation are numerous, including regulation of metabolism, gene transcription, cell growth and division, and cell differentiation (3). Cyclic AMP binds to and is degraded by cAMP phosphodiesterases [PDEs, denoted (10) Figure 1]. The cAMP PDEs can be stimulated via phosphorylation by PKA, leading to reduced cAMP levels and consequently down-regulation of cAMP signaling in a negative feedback loop (22).

\section{THE PKA R SUBUNIT IS A MAJOR INTRACELLULAR CAMP RECEPTOR}

There are two major forms of the PKA holoenzyme, designated PKA type I (PKAI) and PKA type II (PKAII) (3). While PKAI is made by association of the $\mathrm{C}$ subunit with what is known as RI, PKAII contains RII subunits (23-25). RI and RII were initially distinguished based on their different affinity for the ion-exchange resin diethylaminoethyl (DEAE), and therefore elute at different concentrations of $\mathrm{NaCl}(26,27)$. Two known isoforms of each of the RI and RII subunits are described and called RI $\alpha$, RI $\beta$, RII $\alpha$, and RII $\beta$, respectively (28-31). Despite that heterodimers of RI $\alpha$ and RI $\beta$ have been reported to form PKAI, most PKAI holoenzymes are thought to contain either RI $\alpha$ or RI $\beta$ homodimers $(24,32,33)$. The $\mathrm{R}$ subunit isoforms also associate with different sets of proteins, locating the PKA holoenzymes to different subcellular compartments (34-36). All R subunits share the same overall architecture (37). The N-terminus contains a dimerization/docking domain (D/D domain). This is where the $\mathrm{R}$ subunits bind to each other, forming dimers. The $\mathrm{D} / \mathrm{D}$ domain is also the binding site for proteins belonging to the $\mathrm{A}$ kinase anchoring protein [AKAP (see below for details) denoted (11)] family (38). Next to the D/D domain follows a linker region, containing a substrate/autoinhibitor site, including the primary C subunit recognition site (RS1). The RS1 site contains an actual phosphorylation site (P-site) in RII ( $\alpha$ and $\beta$ ), and a pseudo site in RI. In RII the P-site is occupied by a Ser residue (38), making RII a substrate inhibitor of the C subunit. The RI subunits on the other hand represent pseudosubstrates as Ala (RI $\alpha$ ) or Gly (RI $\beta$ ). Carboxy (C)-terminally in the R subunits two cAMP binding domains are located and denoted CBD A and $B$, as previously described $(38,39)$. The various $R$ subunits are differentially expressed in different tissues. Whereas, RI $\alpha$ and RII $\alpha$ are ubiquitously expressed (40-42), RI $\beta$ is primarily found in brain (43), and RII $\beta$ is expressed in endocrine tissues, brain, fat and reproductive organs $(24,44)$. The $\mathrm{R}$ subunit genes are, at least partially, non-redundant as studies of $\mathrm{R}$ subunit null mutated [knockout $(\mathrm{KO})]$ mice reveal altered phenotypes in all four instances of $\mathrm{R}$ subunit ablation. The most pronounced phenotype has been described for an RI $\alpha$ null mutation where the mice displayed severe developmental defects and die at an early embryonic stage (45). Null mutation of the other $\mathrm{R}$ subunits did not show such severe phenotypes. RII $\alpha$-knockouts show reduced ocular dominance plasticity and long-term potentiation (46), as well as a predisposition to hematopoietic neoplasms (47). Ablation of RI $\beta$ was associated with reduced inflammatory response and nociceptive pain (48). In addition, RI $\beta$ KO showed a role for this subunit in tuning hippocampal synaptic plasticity $(49,50)$. Finally, RII $\beta$ KO studies revealed this isoform as important in metabolic and temperature regulation (51-53) as well as motor behavior and neural gene expression (54). Interestingly, null mutation of RII $\beta$ in mice 


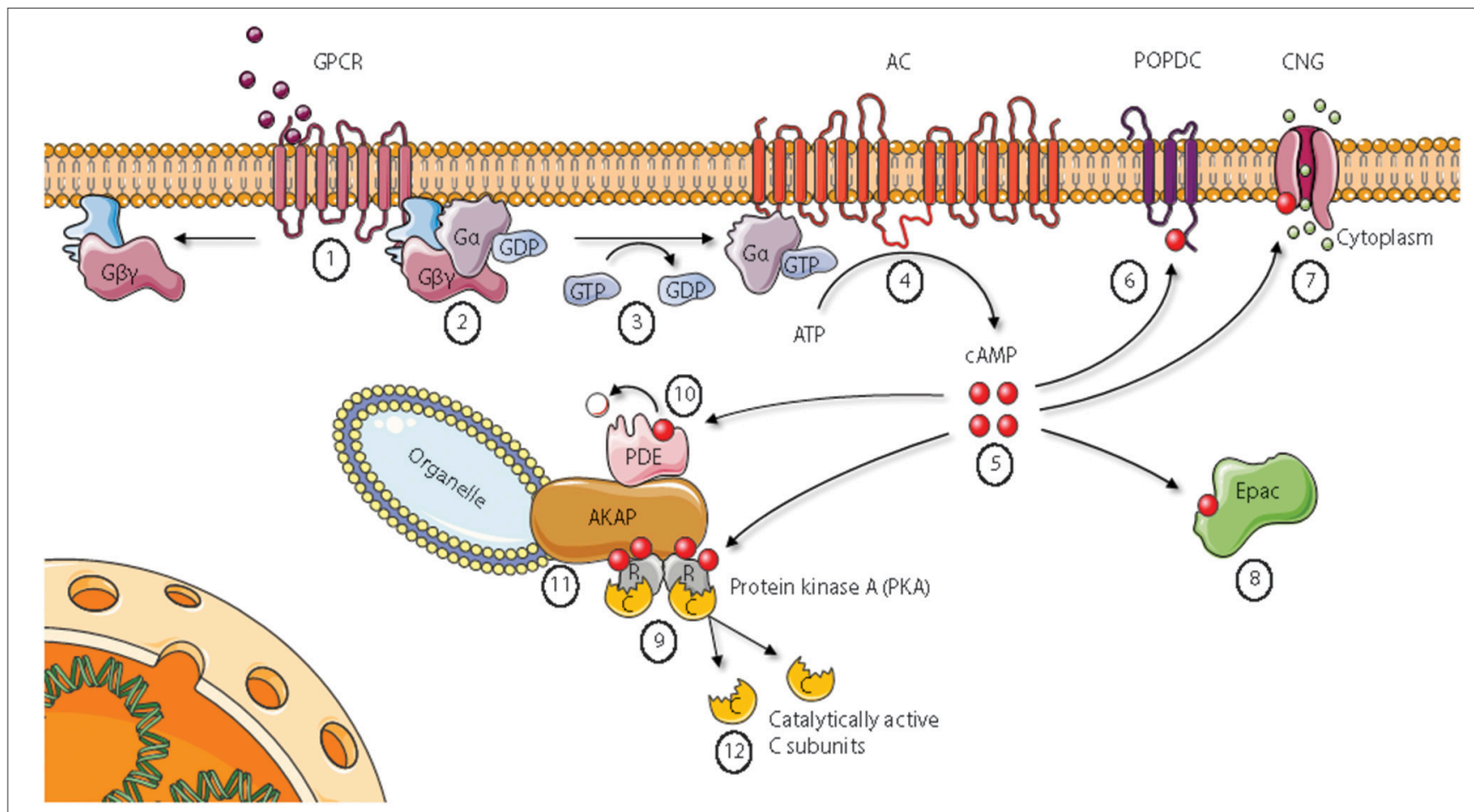

FIGURE 1 | Cyclic AMP signaling pathways. Epac, Exchange protein directly activated by cAMP; AKAP, A Kinase Anchoring Protein; PDE, phosphodiesterase. See main text for details. Figure based on Wong and Scott (2). Figure created using the Servier Medical Art resource (http://www.servier.com).

leads to delayed cardiac aging, including resistance to age-related diastolic dysfunction and a superior global ventricular function compared to wild type (WT) (55).

Recently a report was published demonstrating that the stoichiometric relation between RI and RII is $0.6-1.5 \mu \mathrm{M}$ revealing a 2.5 -fold excess of RII in any given tissue (56). To this end, they also showed that the $\mathrm{C}$ subunit is greatly outnumbered by the $\mathrm{R}$ subunit in that the $\mathrm{R}$ concentration exceeds $\mathrm{C}$ more than 17-fold.

\section{PKA C SUBUNIT VARIANTS}

In humans, two principal $C$ subunit encoding genes are identified: PRKACA and PRKACB, encoding proteins $C \alpha$ and $C \beta$, respectively. In addition, $P R K X$ and the retroposons $P R K Y$ and $P R K A C G$ are identified as PKA $\mathrm{C}$ subunit genes. PRKY and $P R K A C G$ have not been shown to translate into proteins, whereas $P R K X$ is translated into a cAMP-responsive PK which is inhibited by $\mathrm{R}$ subunits (57-61). At physiological conditions, in vitro experiments show that PRKX activity is inhibited by high affinity binding to RI $\alpha$ subunits, whereas RII $\alpha$ subunits only show weak binding (61). Deletion of PRKACA in mice reveals a severe phenotype with most of the offspring dying before or at birth and during the early postnatal period (62). The mammalian PRKACA gene encodes two $\mathrm{C} \alpha$ variants designated $\mathrm{C} \alpha 1$ and $\mathrm{C} \alpha 2$ (63). $\mathrm{C} \alpha 1$ and $\mathrm{C} \alpha 2$ are encoded with different amino $(\mathrm{N})$-terminal ends due to the use of alternative $5^{\prime}$ first exons in the PRKACA gene. C $\alpha 1$ is ubiquitously expressed, and is the main source of PKA activity in most tissues (64). C $\alpha 2$ is exclusively expressed in a late stage of sperm maturation in the testis, and selective ablation of C $\alpha 2$ in mice renders the mice infertile (65). C $\beta$ exists in several splice variants due to the use of four known alternative $5^{\prime}$ exons, giving rise to the proteins $C \beta 1, C \beta 2, C \beta 3$, and $C \beta 4(66,67)$. In addition, $\mathrm{C} \beta 3$ and $\mathrm{C} \beta 4$ may contain additional exons located $5^{\prime}$ of exon 2 termed $a, b$, and $c(68,69)$. C $\beta 1$ is ubiquitously expressed, whereas the other $C \beta$ splice variants are more specifically expressed in tissues like lymphoid and neuronal tissue $(68,69)$. Inactive $C \beta$ subunit variants missing exon 4 have also been identified in nervous tissue (70). Genetic null-mutation of $P R K A C B$ results in a reduced accumulation of visceral fat in mice fed a high caloric diet, and the mice are protected from certain age-related problems, including cardiac dysfunction and hypertrophy (55).

Thus, most of the variability between $\mathrm{C} \alpha, \mathrm{C} \beta$, and their splice variants, is found in the N-terminal parts of these proteins. Several reports have made attempts to document functional features associated with the $\mathrm{N}$-terminal end of the $\mathrm{C}$ subunit which is encoded by exon 1 . The $C \alpha 2, C \beta 2, C \beta 3$, and $C \beta 4$ splice variants are lacking the $\mathrm{N}$-terminal myristoylation site which is seen in both $\mathrm{C} \alpha 1$ and $\mathrm{C} \beta 1$ (66). $\mathrm{C}$ subunit myristoylation is thought to play a regulatory role in activity and localization of the C subunit $(71,72)$. The enzyme $\mathrm{N}$-myristoyl transferase (NMT) catalyzes the covalent attachment of myristic acid onto Gly1. In the unmyristoylated form, the N-terminus of the $\mathrm{C}$ subunit is disordered, and it becomes ordered upon myristoylation (73). The ordered structure that is formed includes the N-terminal amphipathic helix known as the A helix (74). Experiments have 
shown that A kinase interacting protein (AKIP1) binds to the $\mathrm{N}$-terminus of $\mathrm{C} \alpha 1$ (75), implying that the $\mathrm{N}$-tail has a role in protein-protein interactions. Myristoylation leads to increased thermal stability of the $\mathrm{C}$ subunit, and the myristoyl group may localize to a hydrophobic pocket in the $\mathrm{C}$ subunit. In the myristoylated $\mathrm{C}$ subunit, the myristoylation site becomes solvent exposed upon binding to RII, but not RI subunits. This also leads to increased $\mathrm{N}$-terminal flexibility, and the holoenzyme becomes more hydrophobic. This hydrophobicity stimulates association of PKA to membranes $(76,77)$. The latter has recently been substantiated in two recent publications $(56,78)$. In the work by Walker-Gray, they showed by inter- and intralink analysis of $\mathrm{C} \beta$ and RII and using XL-MS that a complex of myristoylated $C \beta 1$ in association with RII $\beta$ and myristoylated and acetylated (palmitate) AKAP was linked to the plasma membrane. This suggests an anchoring function of $\mathrm{C}$ myristoylation of the $\mathrm{C} \beta 1$ subunit which may also account for $\mathrm{C} \alpha 1$ which undergoes myristoylation at the same site as $C \beta 1$.

In addition to the Gly1 myristoylation site, the two modifiable residues Asn 2 and Ser10 are identified only in $C \alpha 1$ and $C \beta 1$. Asn2 may be deamidated into Asp2, whereas Ser10 is a site for autophosphorylation by PKA (71, 79, 80). Deamidated forms have been identified in about one third of all $\mathrm{C} \alpha 1$ and $C \beta 1$ proteins isolated from hearts of pig and cattle, and the localization of the two variants were analyzed by microinjection of each fraction into the cytoplasm of NIH 3T3 cells, showing a relative lower amount of deamidated $\mathrm{C}$ subunit accumulating in the nucleus. This was also reflected by a lower degree of PKA-mediated phosphorylation of the transcription factor CAMP response element-binding protein (CREB) in cells microinjected with the Asp2 form (81). It is believed that deamidation of Asn2 to Asp2 occurs through the non-enzymatic $\beta$-aspartyl shift mechanism $(81,82)$. Ser10 has only been identified as phosophorylated in $\mathrm{C}$ subunit purified from E. coli, and has been proposed to be a transient modification in mammalian $\mathrm{C}$ (81). Deamidation of Asn2 seems to be a prerequisite for Ser10 phosphorylation (83). Ser10 phosphorylation is speculated to be important for $\mathrm{C}$ subunit membrane association controlled by a myristoyl/phosphoserine switch (74). Experiments indicate that phosphorylation of Ser10 and/or the presence of membranes may alter the conformation of the myristoyl group from "myrin" (i.e., myristic acid bound to the hydrophobic pocket) to "myr-out" (74). Much less is known regarding the potential functions of the various $\mathrm{N}$-termini of $\mathrm{C} \beta$ apart from $\mathrm{C} \beta 1$. The $\mathrm{C} \beta 2 \mathrm{~N}$-terminus is the longest of all the $\mathrm{C}$ subunits, with human $P R K A C B$ exon 1-2 encoding 62 residues (excluding the $\mathrm{N}$-terminal Met) (69). C $\beta 2$ has previously been identified in mammals and birds, and the N-terminus includes a stretch of residues predicted to form an amphipathic helix, possibly involved in membrane targeting (67). Human PRKACB exons $1-3,1-4, a, b$, and $c$ are short exons encoding between two and eight residues. $\mathrm{C} \beta 3$ encodes an $\mathrm{N}$-terminal Gly, but experiments indicate that this variant is not myristoylated (66). Seen together, this may suggest that features associated with the very proximal $\mathrm{N}$-terminus may determine 3D structure, membrane binding capacity as well as solubility and may determine splice variant specific features.
Based on the high degree of sequence identity between $\mathrm{C} \alpha 1$ and $C \beta 1$ it may be assumed that they have highly comparable features. However, it has been demonstrated that $\mathrm{C} \alpha 1$ has a threeto five-fold lower $\mathrm{K}_{\mathrm{m}}$ for certain peptide substrates than $\mathrm{C} \beta 1$, in addition to a three-fold lower IC50 for inhibition by the protein kinase inhibitor (PKI) and RII $\alpha$ (84).

To conclude, despite a certain degree of overlapping functions, the various isoforms constituting the PKA holoenzymes may determine the downstream effects of PKA activation (85). For example, ablation of $C \alpha$ but not $C \beta$ has been shown to lead to upregulation of the activation marker CD69 in murine lymphocytes, which was associated with increased responses to allogeneic stimulation as well as reduced sensitivity to cAMPmediated inhibition of $\mathrm{T}$ cell proliferation (86). Moreover, it has recently been identified that $C \beta$ and not $C \alpha$ is necessary for inducing expression of PDE4B, a target for treatment of severe chronic obstructive pulmonary disease (COPD) (87).

\section{SUBCELLULAR ANCHORING OF PKA-A MEANS TO SEQUESTER CAMP EFFECTS}

A vast number of substrates and hence processes are regulated by the cAMP-PKA signaling pathway. Accordingly, a major question is, how specificity is maintained when various hormones binding to their respective receptors stimulate endogenous production of a single second messenger cAMP can elicit highly diverse signals with high precision in time and space. As understood from above, specificity is achieved at many levels, including at the level of GPCR, AC, and PDEs. Another level of specificity in the signaling pathway, which also turned out to be a general mechanism for most intracellular signaling pathways was the discovery of subcellular localization and pools of PKA differentially regulated by the cAMP-inducing receptor agonists, isoproterenol and prostaglandin E1 (PGE1) in the heart (88-91). It was later shown that the receptor for isoproterenol is located at a different place on the cardiomyocytes compared to PGE1 receptor generating distinct intracellular pools of cAMP $(92,93)$. In these and other studies it was also revealed that the effects of isoproterenol and PGE1 as PDE could be differentially regulated by PDE4 and PDE3, respectively (94). The differential effects of agonists and PDE3 strongly points to compartmentalization of cAMP, but also to the colocalization of enzyme complexes, such as PKA and PDEs. Later it has been demonstrated that this occurs through subcellular targeting of PKA, PDEs and other proteins important to signal transduction to a large group of proteins which are designated AKAPs (A kinase anchoring proteins) (95-97). AKAPs are a group of structurally diverse proteins, with a common function, targeting of the $\mathrm{R}$ subunit and hence, confining PKA to discrete locations within the cell. $\mathrm{R}$ subunit binding is conveyed by a targeting domain that anchors the R subunit, and thereby PKA to specific subcellular locations. More than 50 AKAPs have been identified that are expressed in virtually all tissue and cell types examined. These complexes are typically associated with of PKAII holoenzymes as AKAPs were initially shown to bind to the RII subunit with an up to several hundred fold higher affinity compared to the 
RI subunit (98). The nature of the RII binding domain was initially revealed by helical wheel analysis of AKAP13 (also known as AKAP-Lbc) and a peptide termed human thyroid 31 (Ht31) which was derived from the predicted RII binding domain of AKAP13. It is however well established that the PKAI holoenzymes, which are mainly identified in the soluble fraction of the cell, may bind to RI- and dual-specific AKAPs $(95,96)$. They can localize to most cellular organelles including the plasma membrane (AKAP7 and AKAP5), the cytoskeleton (AKAP12 and AKAP13), mitochondria (AKAP1), the Golgi apparatus (AKAP9), vesicles (AKAP11) as well as the nucleus (AKAP 8) (99). Because AKAPs bind RII and RI with different affinities, AKAPs are normally subdivided into three classes; RI-, RII-, or dual-specific (100). The RII binding domain consists of an amphipathic $\alpha$-helix of 14-18 amino acids that binds to the fourhelix bundle formed by the D/D domains of the R dimers. AKAPs may also bind to the D/D domain of RI. However, it has been shown that several dual-specific AKAPs have an additional PKA binding determinant termed RI specifier region. It is located outside the common amphipathic helix motif and contains basic residues that associate specifically with RI and not RII (100). AKAPs also serve as signaling nodes for several participants in the cAMP signaling cascade, including GPCRs (101), ACs (102), Epac (103), protein phosphatatses (PPs) (104), and PDEs (105). In this way AKAPs function as scaffolds that orchestrate signaling events in space and time by forming multicomponent complexes. Thus, AKAPs facilitate cross talk and integration of different signaling pathways and are often referred to as signalosomes (99). This function is well documented by the dynamic association of RI $\alpha$ in the holoenzyme form, associated with $\mathrm{C}$, and in non-C bound form and AKAP11 (106). Day and coworkers demonstrate an AKAP-dependent localization of RI $\alpha$ to multivesicular bodies (MVBs). Binding of RI $\alpha$ to AKAP11 occurs both in RI $\alpha$ holoenzymes and in RI $\alpha$ dimers not bound to C subunits. However, recruitment to MVBs takes place exclusively after the $\mathrm{C}$ subunits are released. Association with MVBs is reversed when C subunits reassociate with the RI $\alpha$ subunits. This documents that AKAPs may direct $\mathrm{R}$ subunit (in this case RI $\alpha$ ) functionality after $\mathrm{C}$ subunit dissociation.

\section{KINASE ANCHORING PROTEINS-C-KAPS}

Proteins that bind the PKA C subunits are diverse and located to all parts of the cell, e.g., the outer membrane, the cytoplasm, and the nucleus. For this group of proteins, we propose the term $\mathrm{C}$ kinase anchoring proteins, C-KAPs. C-KAPs are all proteins that bind directly to the $\mathrm{C}$ subunit and affect its localization. They include substrates and pseudosubstrates such as the RIIand RI subunits, respectively, as well as proteins binding to other parts of the C subunit outside of the active site cleft, such as AKIP. This means we define C-KAPs as distinct from proteins targeting the $\mathrm{R}$ subunits to subcellular compartments through AKAP interactions and proteins that interact transiently as substrates for the $\mathrm{C}$ subunits without targeting the $\mathrm{C}$ subunit to subcellular structures or other scaffolds. Given this definition, the first C-KAP apart from the R subunits to be described was PKI [Figure 2 (1)] (107). There are three isoforms of PKI; PKI $\alpha$, PKI $\beta$, and PKI $\gamma$, and all act as physiological inhibitors of PKA by serving as pseudosubstrates for the C subunit $(108,109)$. As all PKA C subunits except $\mathrm{C} \gamma$ are identical in the catalytic cleft it is assumed that PKI binds with the same affinity and specificity to all $\mathrm{C} \alpha$ and $\mathrm{C} \beta$ isoforms, a feature which is confirmed for $\mathrm{C} \alpha 1$ and $\mathrm{C} \alpha 2$ (110). With respect to the $\mathrm{C} \gamma$ subunit, it is not inhibited by PKI (111). The PKI isoforms contain a nuclear export signal (NES) and is important in active transport of free $\mathrm{C}$ subunits from the nucleus (112). No apparent phenotypical effects of ablating the different PKI isoforms in mice have been demonstrated, even though their different expression patterns imply specific roles $(113,114)$.

Several C-KAPs are expressed in the cytoplasm. One such protein is the small GTPase Rab13 which is involved in tight junction dynamics. Vasodilator-stimulated phosphoprotein (VASP) is a PKA substrate and a key actin cytoskeletal remodeling protein (115). GTP-bound Rab13 interacts directly with PKA C $\alpha$ and inhibits PKA dependent phosphorylation and tight junction associated VASP. This leads to functionally defect tight junctions (116) [Figure 2 (2)].

A number of components of the cAMP signaling cascade have been localized to caveolae which are a part of lipid rafts and function as endocytic and exocytic compartments at the plasma membrane of most cells. Caveolin-1, which is the main component of caveolae may be considered a C-KAP, as it binds and targets the $\mathrm{C}$ subunit to the cell membrane $(117,118)$. The PKA C subunit associates through binding of the Caveolin-1 scaffolding domain on the C-terminus and the binding has been shown to inhibit $\mathrm{C}$ subunit enzymatic activity (118) [Figure 2 (3)]. This may explain why Caveolin1 KO mice revealed hyperactive PKA (119). Caveolin-1 KO mice also have abnormal lipid homeostasis with phenotypic characteristics associated with type II diabetes, a feature that has been linked to disturbances in PKA-mediated phosphorylation. To this end it has been shown that Caveolin-1 bound C subunit also binds to perilipin, which is a protein that covers and protects lipid droplets, can be phosphorylated by PKA, and co-immunoprecipitates with Caveolin-1-PKA C from adipocytes upon $\beta$-adrenergic stimulation (120). Moreover, it has been shown that PKA-mediated perilipin phosphorylation and subsequent release of lipids from lipid droplets is dependent on Caveolin-1 induced formation between PKA C and perilipin (119). Furthermore, optic atrophy 1 (OPA1), a protein known to regulate mitochondrial dynamics, was identified as a dualspecificity AKAP that associates with lipid droplets. OPA1 targets PKA to lipid droplets for the purpose of hormonal control of perilipin phosphorylation and lipolysis (121).

p75 neurotrophin receptor $\left(\mathrm{p} 75^{\mathrm{NTR}}\right)$ may be considered a cell membrane-bound C-KAP [Figure 2 (3)]. Ligands for $\mathrm{p} 75^{\mathrm{NTR}}$ are the neurotrophins, a class of growth factors that regulate the survival, differentiation, growth, and apoptosis of neurons. $\mathrm{p} 75^{\mathrm{NTR}}$ has been shown to interact with and be phosphorylated by the PKA C $\beta 4$ ab splice variant (122). Moreover, activation of the cAMP and PKA pathway was required for translocation of $\mathrm{p} 75^{\mathrm{NTR}}$ to lipid rafts and for the 


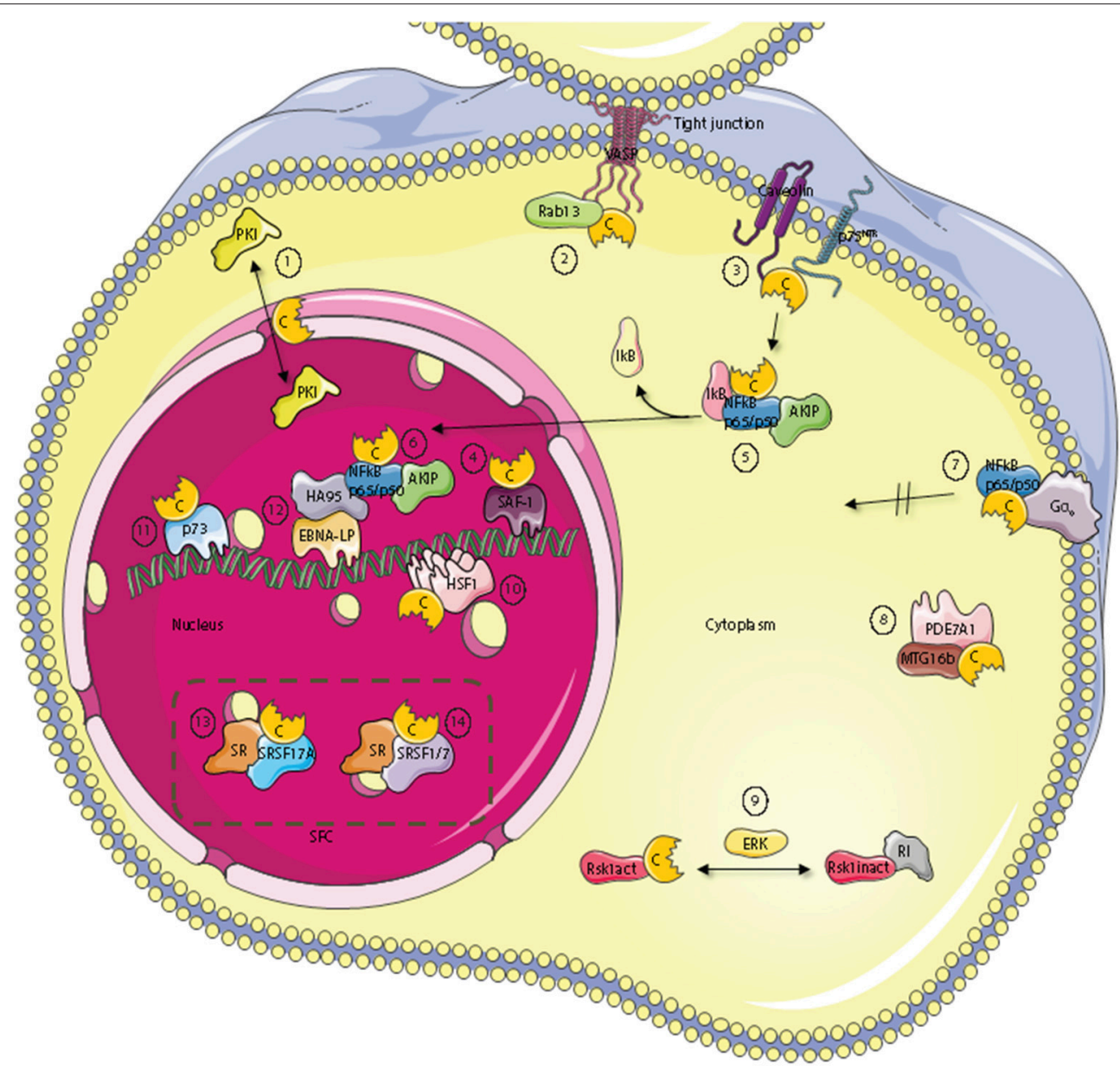

FIGURE 2 | Subcellular localization of C kinase anchoring proteins - C-KAPs. The PKA C subunit associates and regulates the activity of proteins located to multiple cellular compartments and molecules. These compartments include the outer cell membrane, the cell cytoplasm and the cell nucleus. In the nucleus, C-KAPs co-locate the PKA C subunit with DNA and components of the splicing factor compartment (SFC). In the cytoplasm the PKA C subunit in addition to associate with the PKA R subunit interacts with the PKA inhibitor PKI (1), the small G protein Rab13 (2), PDE7A1 (8) the Rsk1 kinase through regulation by ERK (9), and finally IkB (5) which is a component of the cytoplasmic NFkB/AKIP complex. In the outer membrane compartment PKA C subunits associate with caveolin-1, p75 NTR (3), and the heterotrimeric G protein $\mathrm{G} \alpha 0$ (7). In the nucleus, the PKA C subunit regulates DNA activity through interaction with SAF-1 (4), HSF-1 (10), HA95 (12), and p73 (11). Finally, the PKA C subunit is also involved in regulating mRNA splicing in SFC by direct interaction with serine and arginine (SR) proteins such as SFSR17A (13), SRSF1 and SRSF7 (14).

receptors biochemical and biological activities. Furthermore, p $75^{\text {NTR }}$ has also been demonstrated to associate with Caveolin (123).

An important downstream effect of neurotrophin bound to $\mathrm{p} 75^{\mathrm{NTR}}$ is to activate the nuclear factor $\kappa$-light-chainenhancer of activated $\mathrm{B}$ cells $(\mathrm{NF} \kappa \mathrm{B})$ pathway (124). $\mathrm{NF} \kappa \mathrm{B}$ has been implicated as an important transcription factor for serum amyloid A (SAA) which is a family of plasma proteins that is linked with several inflammatory diseases, including amyloidosis, rheumatoid arthritis and atherosclerosis. Activation of has further been linked to SAA-activating factor 1 (SAF) which has been shown to associate with PKA C $\alpha$ (125) [Figure 2 (4)]. In line with this, activation of SAF-1 is cAMP-dependent and cAMP increases the transactivating and DNA-binding properties of SAF-1 (126).
NFKB is a member of the Rel family of rapid-acting transcription factors. The NFאB p65/p50 dimer is kept inactive in the cytosol in complex with the protein inhibitor of $\kappa \mathrm{B}$ (IкB). IкB which masks the nuclear localization signal (NLS) of

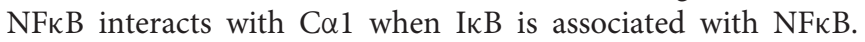
$\mathrm{C} \alpha 1$ is inactive until stimulation and activation of $\mathrm{NF} \kappa \mathrm{B}$ by agents such as cytokines and reactive oxygen species (ROS). This leads to the release and degradation of I $\mathrm{B}$ with subsequent cAMP-independent activation of PKA C [Figure 2 (5)]. The C subunits have been shown to phosphorylate Ser276 in the p65 subunit. This enhances $\mathrm{NF} \kappa \mathrm{B}$ transcriptional activity markedly and increases the expression of NFкB downstream target genes involved in e.g. inflammation, cell proliferation and survival. Interestingly, AKIP which was first identified as a PKA C-binding protein (75) is also a p65 interaction partner (127) [Figure 2 (5)]. 
According to this observation it has been suggested that binding of the $\mathrm{C}$ subunit and AKIP to the $\mathrm{p} 65$ subunit encompass PKAdependent phosphorylation and regulation of NFKB dependent transcription (127). Together this also suggests that AKIP1 acts as a molecular scaffold that simultaneously binds and coordinates PKA C and p65 activity. In line with this it was shown that AKIP1 regulates NFKB nuclear translocation (128) [Figure 2 (6)]. Another aspect of PKA C and NFKB interaction has been documented according to the fact that this complex is activated when the heterotrimeric $\mathrm{G}$ protein Go interacts directly with the $\mathrm{C}$ subunit independent of the $\mathrm{R}$ subunit [Figure 2 (7)]. This suggests that $\mathrm{G} \alpha \mathrm{o}$ is a C-KAP as well. Interestingly, when $\mathrm{C}$ binds to $\mathrm{G} \alpha$ o this prevents $\mathrm{C}$ from translocating to the nucleus but does not inhibit catalytic activity (129). The fact that $G \alpha$ o interacts with both PKA holoenzyme and free $\mathrm{C}$ subunits provides evidence that active $\mathrm{C}$ can be released from $\mathrm{R}$ and positioned in an active state in close proximity to relevant substrates as well as the $\mathrm{R}$ subunit for rapid association, holoenzyme formation, and presumably inactivation when cAMP is degraded. With respect to cAMP degradation, the PDE variant PDE7A1 does not only degrade cAMP to regulate PKA activity (130). PDE7A1 also regulates $\mathrm{C}$ subunit activity through direct interaction between the $\mathrm{C}$ subunit and the $\mathrm{N}$-terminus of PDE7A1 [Figure 2 (8)]. The PDE7A1 N-terminus which contains two PKA pseudosubstrate sequences may be considered a C-KAP (131). It should also be mentioned that PDE7A1 interacts with myeloid translocation gene 16b (MTG16b) which is a dual specific AKAP $(132,133)$. Although the function of the AKAP-MTG16b/PDE7A1/PKA complex is not fully understood [Figure 2 (8)], it is likely that this structure as is the case with the Goo/NF- $\mathrm{kB} / \mathrm{C}$-subunit complex discretely regulates spatiotemporal effects of PKA. Furthermore, as the $\mathrm{G} \alpha \mathrm{o} / \mathrm{NF}-\kappa \mathrm{B} / \mathrm{C}$-subunit complex is also identified in $\mathrm{T}$ cells it is suggested that it may be a key factor of the signaling complex regulating $\mathrm{T}$ cell activation (134).

A major signaling pathway in eukaryotic cells is the mitogenactivated protein kinase (MAPK) pathway which is implicated in regulating cell growth, differentiation and apoptosis. A typical MAPK pathway consists of a cascade of three successive phosphorylations exerted by a MAPK kinase kinase (MAPKKK e.g., Raf), a MAPK kinase (MAPKK, e.g., Mek), and a MAPK (e.g., Erk). MAPKs target other proteins such as kinases known as the MAPK-activated protein kinases (MAPKAPK) that belong to the $\mathrm{Ca}^{2+/}$ calmodulin-dependent protein kinases. Among these kinases we find the ribosomal-S6-kinases (RSKs) which represent points of cross-talk between the PKA pathway and the MAPK pathway. RSK1 is a serine/threonine kinase with important functions in cellular growth control and proliferation (135). RSK1 interacts with PKA RI in its unphosphorylated and inactive state while activated RSK1 binds directly to C subunits (136) [Figure 2 (9)]. Binding of RSK1 to RI decreases the interaction between RI and PKA C subunit while the binding of active RSK1 to the $\mathrm{C}$ subunit increases the interaction between the PKA C and $\mathrm{R}$ subunits. These findings indicate that RSK1 acts both as a C-KAP and AKAP involved in a negative feedback loop of PKA activity where PKA can trigger phosphorylation of RSK1 through activation of ERK. Phospho-RSK1 will then promote association of the PKA holoenzyme (137). At the same time, through the association with PKA, D-AKAP1 serves as a necessary nuclear anchor for RSK1. D-AKAP1 also binds protein phosphatase 2A (PP2A) that can dephosphorylate and thus regulate RSK1 activity (138).

In response to heat shock or other physiological stresses, heat shock factor (HSF) rapidly oligomerises into DNA-binding trimers, accumulates in the nucleus and acts as a transcription factor that regulates the expression of heat shock proteins (HSP). HSPs belong to a class of functionally related proteins involved in the folding and unfolding of other proteins (139). This process involves activating posttranslational modifications and the HSF isoform HSF1 has been shown to be sumoylated and acetylated as well as heavily phosphorylated (140). Hyperphosphorylation of HSF1 is correlated with transcriptional competence and slow dissociation of active trimers (141). Moreover, later it has been shown that it acts as a C-KAP as HSF1 binds to PKA C $\alpha$ and is activated by PKA-dependent phosphorylation [Figure 2 (10)]. This again permits HSF1 to accumulate in the nucleus where it activates transcription of HSP70.1 (142). The latter is consistent with the observation that the cAMP and PKA-pathway regulates HSP70 promoter activity (143).

Another protein important for the regulation of cell growth and proliferation is p73, which is a structural and functional homolog of the widely known p53 tumor suppressor protein (144). Evidence suggests that p 73 can bind to the p53-responsive element and transactivate an overlapping set of p53 target genes, thus, leading to the induction of G1/S cell cycle arrest. p73 is expressed as multiple isoforms arising from alternative splicing

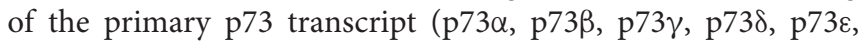
$\mathrm{p} 73 \eta$, and $\mathrm{p} 73 \zeta)$. p73 $\alpha$, but not $\mathrm{p} 53$, has been demonstrated to be phosphorylated by and bind to the PKA $C \beta$ subunit, and may therefore be considered a C-KAP [Figure 2 (11)] (145).

Taken together these reports demonstrate regulation of activity and location of $\mathrm{C}$ and its interaction partners both in the cytoplasm as well as the nucleus. It has further been reported that the PKA holoenzyme may localize within the nucleus (146). Nuclear localization of the PKA holoenzyme is however controversial and remarkably few AKAPs have been demonstrated to reside within this cellular compartment in interphase cells. The present dogma suggests that PKA acts in the nucleus when the $\mathrm{C}$ subunit is transferred to the nucleus upon cAMP stimulation. Hence, it is likely that several nuclear CKAPs exist. Homologous to AKAP95 (HA95), which shows high homology to AKAP95, binds the PKA C subunit independent of $\mathrm{R}$ in the nucleus and may be considered a C-KAP (147) [Figure 2 (12)]. HA95 is a nuclear protein and contains a NLS. The gene encoding HA95 probably arose due to a gene duplication of AKAP95 and may have survived evolution because it solely binds the $\mathrm{C}$ subunit and does not compete with AKAP95 for R subunit binding (147). HA95 activity is associated with several nuclear processes, including shuttle protein activity by binding to RNA helicase A and the activation of the retroviral constitutive transport element (148). HA95 is also involved in regulation of nuclear envelope dynamics (149), DNA replication (150), and regulation of the histone deacetylase (HDAC) pathway 
(151). Although conclusive evidence lacks, these reports may imply that there is a direct link between cAMP and PKAdependent regulation of various nuclear events and $C$ subunit binding to HA95. However, support for a direct binding of $\mathrm{C}$ to HA95 comes from experiments on Epstein-Barr virus (EBV) infected $\mathrm{B}$ cells. We have demonstrated that binding of the C subunit to HA95 is required for EBV infection $(152,153)$. In these experiments, HA95 was also shown to coimmunoprecipitate with the EBV co-activating nuclear protein EBNA-LP from EBV-transformed lymphoblastoid cells. It has been suggested that HA95 binds to the EBNA-LP repeat domain which is the principal co-activator of virus transcription. In this way, EBNA-LP co-localizes with HA95 and the C subunit [Figure 2 (12)]. Moreover, C subunit expression down-regulated the strong co-activating effects of EBNA-LP with EBNA-2 which also regulates the expression of the EBV oncogene, LMP1. Interestingly, over-expression of the C subunit or HA95 downregulates LMP1 expression in EBV-infected cells. Together this demonstrates a functional consequence of co-locating $\mathrm{C}$ with C-KAP, in this case with HA95 and EBNA-LP to affect transcription from specific promoters. In this context it is interesting to note that DNA-protein kinase (DNA-PK) also associates with the EBNA-LP/HA95/PKA-C subunit complex (154). Together this demonstrates that PKA targeting is involved in regulating the complex processes of gene transcription. An interesting question is then, whether PKA targeting is required for precursor-messenger RNA (pre-mRNA) transport and processing.

During the last decade accumulating evidence shows that PKA C interaction with other proteins is involved in regulating precursor-messenger RNA (pre-mRNA) splicing. Pre-mRNA splicing is a highly complex process in the eukaryotic cell and involves a tight regulation of protein-protein, protein-DNA and protein-RNA interactions in time and space (155). We have shown that PKA C co-locates with splicing factor compartments (SFC) in the nucleus and that PKA promotes distal splicing of the E1A minigene. We were also able to show that some of the most heavily PKA phosphorylated proteins belong to the family of serine and arginine rich proteins, or SR-proteins. Some of the proteins phosphorylated were the SR splicing factors SRSF1, SRSF2, and SRSF9 (156). It has previously been demonstrated that the SR proteins have central roles in the regulation of constitutive and alternative RNA splicing (157). Later it has been demonstrated that both $\mathrm{R}$ and $\mathrm{C}$ subunits of PKA can bind to splicing factor arginine/serine-rich 17A (SFSR17A) defining this protein as an AKAP as well (158) [Figure 2 (13)]. SFSR17A targets PKA in close proximity to several members of the SR family of proteins. Furthermore, several independent reports show that the PKA C subunit interacts with the SR protein SRSF1 (159-161). PKA-dependent phosphorylation of SRSF1 was found to enhance its RNAbinding capacity (159), and to modulate its activity as a splicing regulator (159-161). Furthermore, another SR protein, SRSF7 is not only phosphorylated by but also interacts with $\mathrm{C} \alpha 1$ (161) [Figure 2 (14)]. Also, the adenoviral splicing factor L4$33 \mathrm{~K}$ is phosphorylated by PKA and DNA-PK. Interestingly, the two kinases have opposite effects on alternative splicing of virus-specific proteins (154). Finally, the G-patch domain and KOW-motifs containing protein (GPKOW) has been shown to be a nuclear protein that binds RNA in a PKAregulated fashion (162). For a summary of known C-KAPs see Table 1.

\section{DETERMINANTS FOR THE REGULATION OF C SUBUNIT ACTIVITY}

Together, these reports imply that PKA is involved in the regulation of multiple steps in the splicing process by phosphorylation. This also demonstrates that the process requires discrete positioning of the $\mathrm{C}$ subunit in proximity to relevant substrates. This raises the question, what are the determinants in the $\mathrm{C}$ subunit dictating localization and binding to other proteins? The inhibitory site of the $\mathrm{R}$ subunit vs. the $\mathrm{C}$ subunit is a distinguishing feature between the RI and RII isoforms (163). The RII subunits have a phosphorylation site (P-site) in their inhibitor motif and therefore act both as substrates and inhibitors. By contrast, the RI subunits are encoded with Ala or Gly at the RII P-site and thus, act as pseudosubstrates. Despite that both RI and RII bind C with a sub nanomolar $\mathrm{Kd}(0.1 \mathrm{nM})$ the mechanism of binding is different. RI, but not the RII subunits, requires ATP and divalent cations to form stable interactions (31, 164).

Moreover, autophosphorylation of the P-site in RII subunits promotes holoenzyme dissociation.

The structure of the C:RI, C:RII and C:PKI interactions show major similarities in how catalytic activity is regulated as the regions $\mathrm{P}-3$ to $\mathrm{P}+1$ in the $\mathrm{C}$ subunit are occupied by both RI, RII as well as PKI upon binding. It should also be noted that the mechanism of PKI binding to the active cleft in C is more similar to that of RI than RII, both being pseudosubstrates and needing ATP and two divalent cations for stable interactions.

As several of the C-KAPs apart from R and PKI also inhibit the $\mathrm{C}$ subunit upon binding, a highly relevant question is whether C-KAPs share the same mechanism of inhibition as R and PKI. In the case of Caveolin-1, it has been demonstrated that residues between Trp85 and Trp98 associate with several amino acids scattered between Phe54 and Tyr247 in the C subunit (165). Moreover, when PDK1 phosphorylates the C subunit at Thr197, this involves anchoring of the C-terminal hydrophobic motif Phe-x-x-Phe to the small lobe of PDK1 (166). It has also been shown that Go $\alpha$ through its GTPase domain interacts directly with C $\alpha 1$ (129). However, few of these papers mapped the domains in the $\mathrm{C}$ subunit responsible interaction with the C-binding protein. One example of mapping of such domains has been done by studying the Ca1:AKIP1 interaction $(75,167)$. In these two reports it was demonstrated that AKIP1 binds to the A helix residues $15-30$ in the C $\alpha 1$ subunit and that this interaction is the mechanism responsible for targeting the $\mathrm{C}$ subunit to the nucleus. This may suggest that the $\mathrm{C}$ subunit $\mathrm{N}$-terminal end is involved in targeting the kinase to relevant target proteins and hence subcellular compartments 
TABLE 1 | Overview of selected C kinase anchoring proteins (C-KAPs).

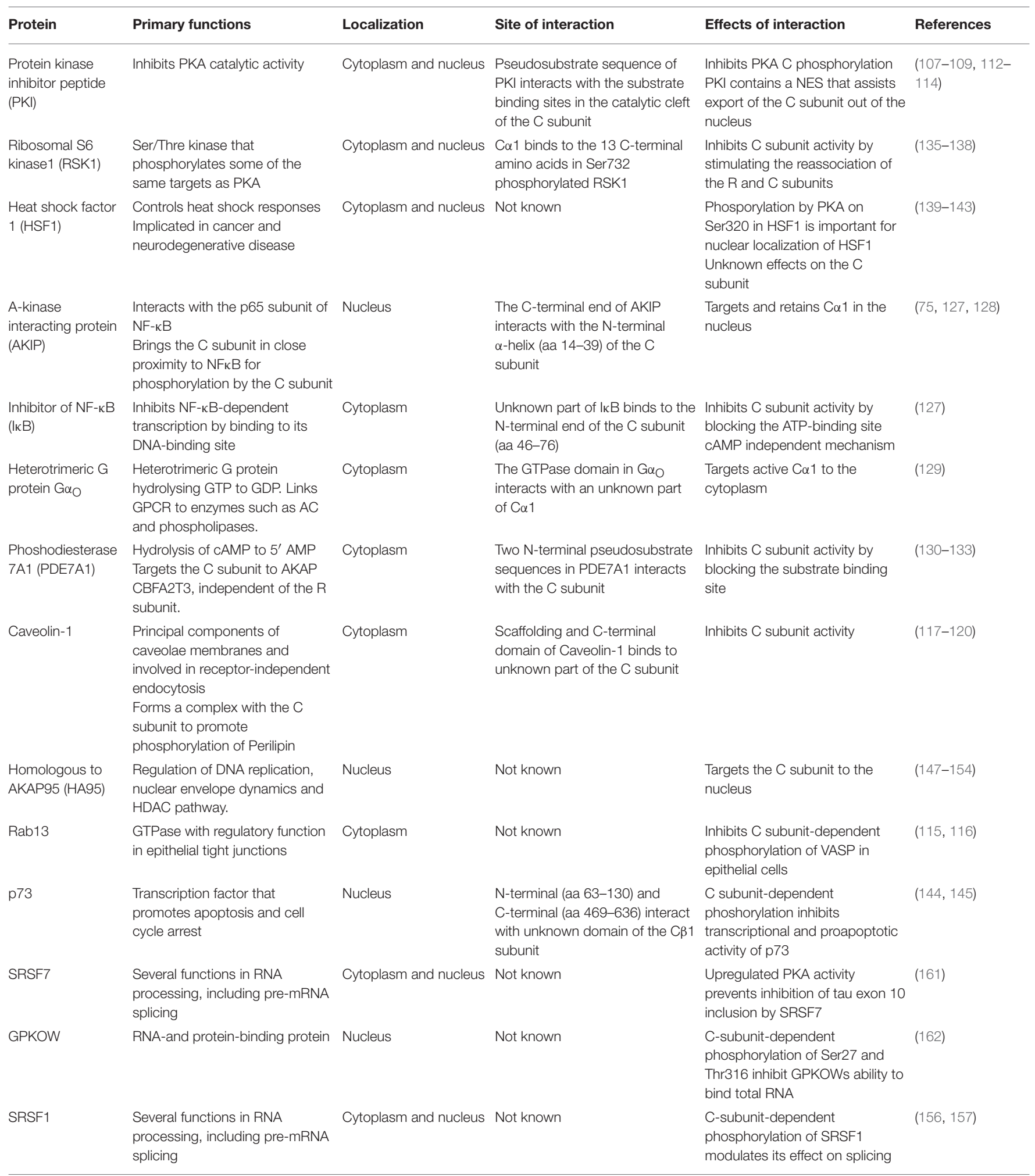

independent of the $\mathrm{R}$ subunit. However, the specificity in this form of targeting remains elusive. It has been speculated that splice variant-specific features of the $\mathrm{C}$ subunits which are associated with the first exon may play an important role. In addition, anchoring of $\mathrm{C} \alpha 1$ and $\mathrm{C} \beta 1$ may involve myristoylation (56). 


\section{CATALYTIC SUBUNIT STRUCTURAL FEATURES AS DETERMINANT FOR PKA SPECIFICITY}

The $C \alpha 1$ and $C \beta 1$ proteins are both made up of 350 aa residues, containing only short $\mathrm{N}$ - and C-terminal segments that are not part of a conserved catalytic core comprising $\mathrm{C} \alpha 1 / \mathrm{C} \beta 1$ residues 40-300 (168). Whereas, the flanking $\mathrm{N}$ - and C-terminal sequences are more specific to the $\mathrm{C}$ subunit, and hence vary considerably the catalytic core consists of a large $\mathrm{C}$-terminal lobe which is also named the C-lobe or large lobe, and a smaller $\mathrm{N}$ terminal lobe also known as the N-lobe or small lobe (Figure 3A)
(171). The large lobe is shaped by seven $\alpha$-helices in addition to contributing to the formation of a sheet of four antiparallel $\beta$-strands in the surface facing the cleft between the two lobes (172). The large lobe contains most of the substrate-binding surface as well as much of the catalytic machinery (85). The small lobe, mostly composed of $\beta$-strands, five in total in an antiparallel orientation in a single sheet, contains most of the residues binding to ATP (172). The small lobe also contains two helices; the $\alpha \mathrm{B}$ and $\alpha \mathrm{C}$ helix (172). The segment that connects the small and large lobes is called the hinge region (173). The cleft between the small and large lobes has been termed the active site cleft. This cleft shapes the ATP binding pocket, with the
A

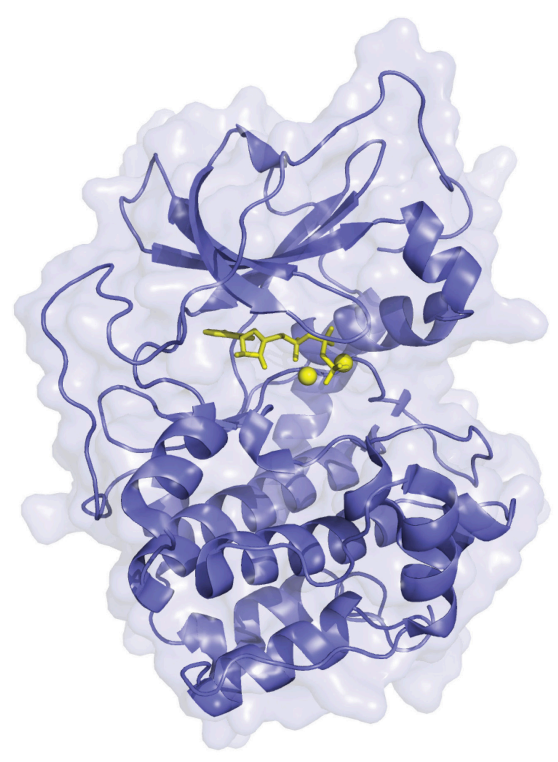

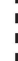

;

\section{Small lobe}

Act. site cleft

Large lobe

B

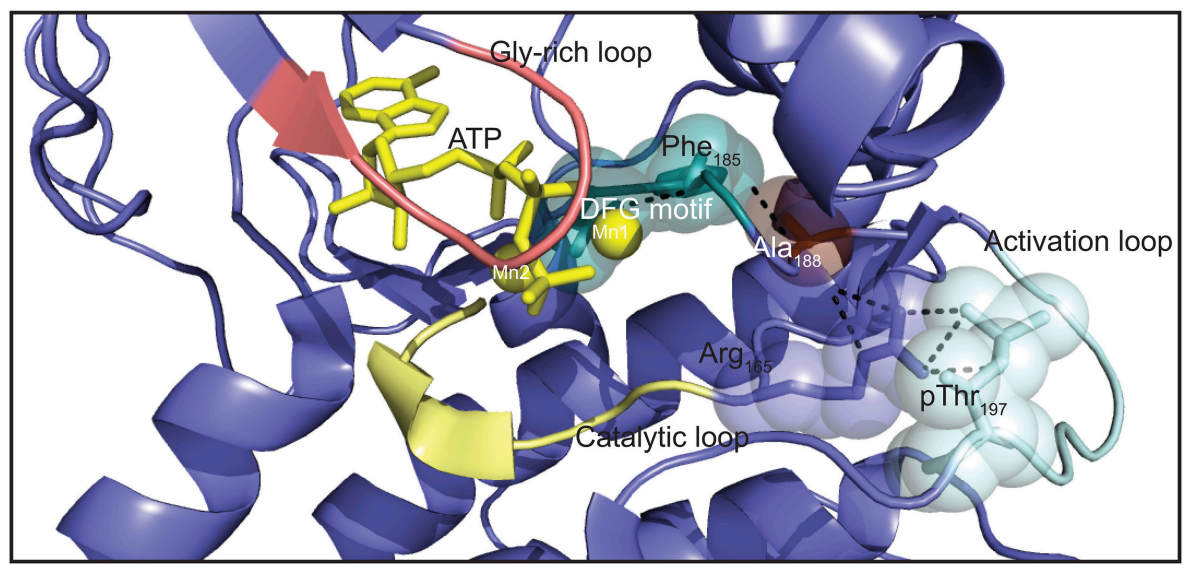

FIGURE 3 | Three dimensional structure of the PKA C subunit. (A) The C subunit is composed of a small lobe, large lobe, and an active site cleft with a binding site for an ATP molecule (yellow sticks) and two Mg2+ ions (yellow spheres). The figure is based on the experimental structure with Protein Data Bank (PDB) identifier 3FJQ (169). (B) Schematic representation of the active site cleft of PKA C $\alpha 1$. Motifs and residues described in the text are indicated. Dashed lines indicate the chain of interactions leading from pThr197 to Phe185 in the DFG motif when the enzyme is in the active conformation. The structure is solved with $\mathrm{Mn}^{2+}$ as the divalent cations, although $\mathrm{Mg}^{2+}$ is thought to be the most relevant biological chelating agent (170). ATP and the $\mathrm{Mn}^{2+}$ ions are shown in yellow, and the DFG motif (teal), Gly-rich loop (salmon), catalytic loop (yellow), and activation loop (cyan) are also highlighted. PDB identifier 3FJQ (169). 
$\gamma$-phosphate facing outwards toward the solute and substratebinding site. Most of the highly conserved residues of $\mathrm{C} \alpha$ and $\mathrm{C} \beta$ are located around the active site cleft. ATP functions as "glue" coupling the small and large lobe together, partially through forming hydrogen bonds with residues in the hinge region (173). Hence, in the absence of ATP the catalytic cleft is relatively uncoupled (174).

Several structural motifs and residues important for function are identified in the catalytic core (Figure 3B). The activation loop (residues 191-197) includes Thr197, which has to be phosphorylated in order for the $\mathrm{C}$ subunit to be catalytically active. Phosphorylation of Thr197 leads to a cascade of interactions in the protein structure, contributing to organizing the kinase in the active conformation (see below) (175). The catalytic loop (residues 166-171) contains several residues important for catalysis. One of the most flexible segments of the catalytic core is the glycine-rich loop (residues 50-55) $(172,176)$. This loop is important for positioning of the $\gamma$-phosphate of ATP for phosphoryl transfer during catalysis (174). The $\mathrm{Mg}^{2+}$ positioning loop (residues 184-187), containing the DFG (AspPhe-Gly) motif (residues 184-186), is among the most conserved segments encompassed in the catalytic core. The catalytic core not only binds an ATP molecule, but also has binding sites for two divalent cations, preferentially magnesium ions $\left(\mathrm{Mg}^{2+}\right)$ termed activating and inhibitory $\mathrm{Mg}^{2+}$, or $\mathrm{Mg} 1$ and $\mathrm{Mg} 2$, respectively, which are necessary for catalysis (170), but also RI binding (177). The traditional view has been that in presence of ATP, the binding affinity for $\mathrm{Mg} 1$ is higher than for $\mathrm{Mg} 2$, and binding of $\mathrm{Mg} 2$ is thought to stabilize the protein but also to inhibit catalysis $(170,178-180)$. Other reports have suggested that the presence of two $\mathrm{Mg}^{2+}$ in the active site of other related eukaryotic protein kinases (ePKs) such as CDK2 is necessary for efficient phosphoryl transfer, but also leads to stabilizing the binding of $\mathrm{ADP}$ to the active site, which is the rate-limiting step of the catalytic cycle (181). Moreover, $\mathrm{Ca}^{2+}$ may exist in local high concentrations near calcium channels, and it is proposed that fluctuations in $\mathrm{Ca}^{2+}$-concentrations may influence $\mathrm{C}$ subunit function through reduced enzyme activity and PKI affinity (182). After phosphorylation of Thr197, the interaction cascade that is initiated leads to optimal orientation of Asp184 in the DFG motif for coordination of the $\gamma$-phosphate of ATP for phosphoryl transfer. It is believed that $\mathrm{Mg} 1$ interacts with the $\beta$ - and $\gamma$ phosphates of ATP and Asp184, while Mg2 is bound by the $\alpha$ and $\gamma$-phosphates of ATP and the side chain of Asn171 of the catalytic loop $(179,180)$.

We and others have shown the crucial importance of the Gly186 residue in $\mathrm{C} \alpha(\mathrm{C} \alpha 1$ numbering) for catalytic activity. We performed a thorough search for naturally occurring mutations in the human PRKACA gene using both publicly available databases as well as through sequencing of exons $2-10$ in 498 individuals (183). The search revealed several missense mutations, including Arg45Gln, Ser109Pro, Gly186Val, and Ser263Cys. Kinase activity and R subunit binding of the mutated C subunits was determined. Mutation of residues 45 and 263 did not significantly alter catalytic activity or R subunit binding. Mutation of Ser109 on the other hand led to decreased kinase activity, whereas $\mathrm{R}$ subunit binding was unaltered. Mutation of
Gly186 to Val however, rendered the kinase completely inactive, and the resulting $\mathrm{C}$ subunit was unable to form holoenzymes with RI subunits, both confirming Gly186 as crucial for catalytic activity and instrumental in divalent cation binding.

The Local Spatial Pattern (LSP) alignment method, developed by Kornev et al. $(175,184)$, has revealed two conserved spatial motifs in ePKs. The motifs, termed Catalytic (C-) and Regulatory (R-) spines (Figure 4A), were identified as necessary structural motifs in catalytically active kinases. For an intact C-spine, the adenine nucleobase of ATP needs to bind to the active site. In PKA, the R-spine depends on phosphorylation of Thr197 in the activation loop. Equivalent Thr residues serve the same regulatory function in other kinases. Thus, assessment of the $\mathrm{C}$ - and R-spines in a kinase structure is helpful in determining whether a kinase is catalytically active or not.

The $\mathrm{N}$ - and C-terminal sequences outside of the kinase core are designated N- and C-tail, respectively (Figure 4B). Both tails are anchored to the core and facilitate its active conformation (85, 171). Except for PKI, C subunit interactions are predominantly mediated through binding to either the $\mathrm{C}$ - or $\mathrm{N}$-tail $(63,75,185)$. The C-tail is divided into three segments; the C-lobe tether (CLT), $\mathrm{N}$-lobe tether (NLT), and the active site tether (AST). When PKA $\mathrm{C}$ is phosphorylated in the activation loop, the CLT and NLT are quite stable and seem to play an important allosteric role in organizing the active conformation (85). Most AGC kinases appear to be activated by the kinase PDK1, which is an AGC kinase itself, docking to the NLT of the C-tail (Figure 4B, "PDK1 recognition site"). Thus, the $\mathrm{C}$-tail is a conserved structure in all AGC kinases (85). The CLT contains a PxxP (Pro-x-x-Pro) motif (residues 313-316 in PKA C $\alpha 1$ ) (Figure 4B, "PxxP motif"), which is also conserved in almost all AGC kinases. The PxxP motif may represent a site for allosteric regulation of AGC kinase activity, possibly by binding to $\mathrm{SH} 3$ domains, which recognize Pro-rich regions $(85,186)$. The AST is more dynamic and contains Phe327 which is a part of the ATP binding site, and Tyr330 which is essential for the closed conformation of the enzyme (85).

\section{STRUCTURAL RELATIONSHIPS OF THE N-TERMINAL END OF THE C SUBUNIT AS DETERMINATES FOR THREE DIMENSIONAL STRUCTURE AND SUBCELLULAR TARGETING}

There are isoform-specific sequence variations in the $\mathrm{N}$-tail of the PKA C subunit. The role and function of $\mathrm{C} \alpha 1$ and $\mathrm{C} \beta 1 \mathrm{~N}$ terminal modifications are largely unknown but may influence localization, activity and interactions of the $\mathrm{C}$ subunit with other proteins (187).

Recently we performed alignments of exon 1-1 encoded $\mathrm{C} \alpha 1 / \mathrm{C} \beta 1$ across species after the gene duplication yielding $\mathrm{C} \alpha$ and $\mathrm{C} \beta$ isoforms, and pre-duplication catalytic subunit [designated C1, (188)] residues reveals several conserved features in the N-terminus during evolution of the $\mathrm{C}$ subunit. Out of all 15 positions, position 1 and 2 is invariably Gly1 and Asn2 in both $C \alpha 1$ and $C \beta 1$, as well as $C 1$, an ancient form of $C \alpha$ 


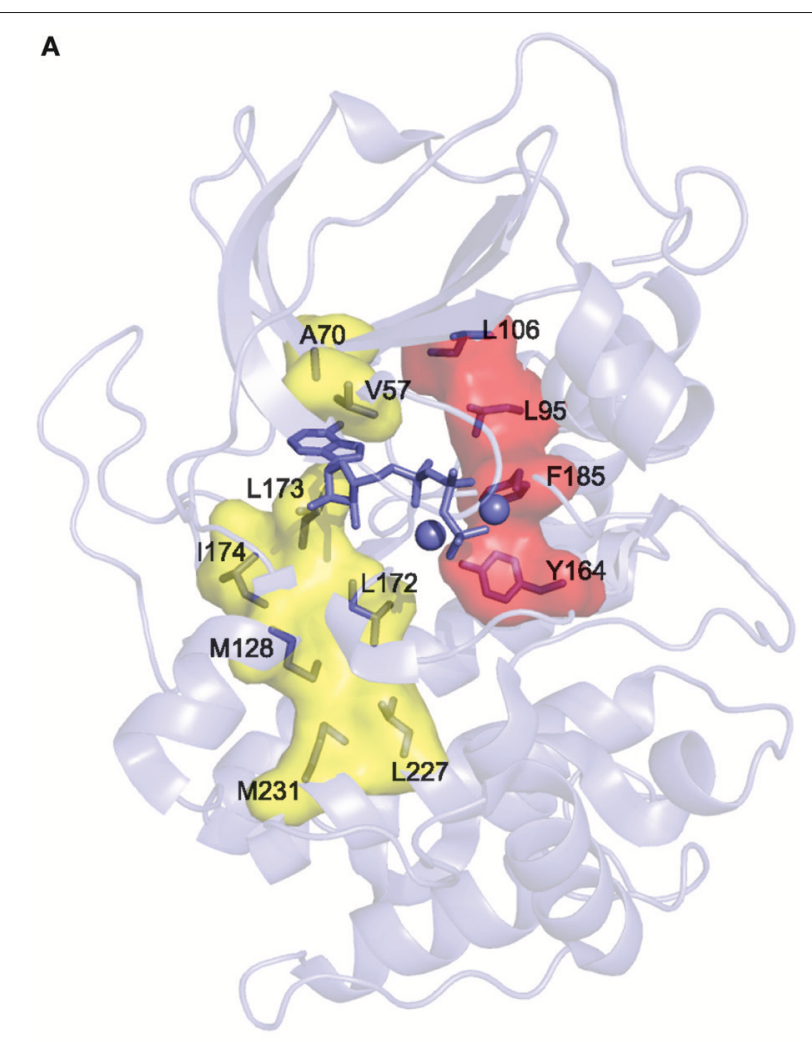

B

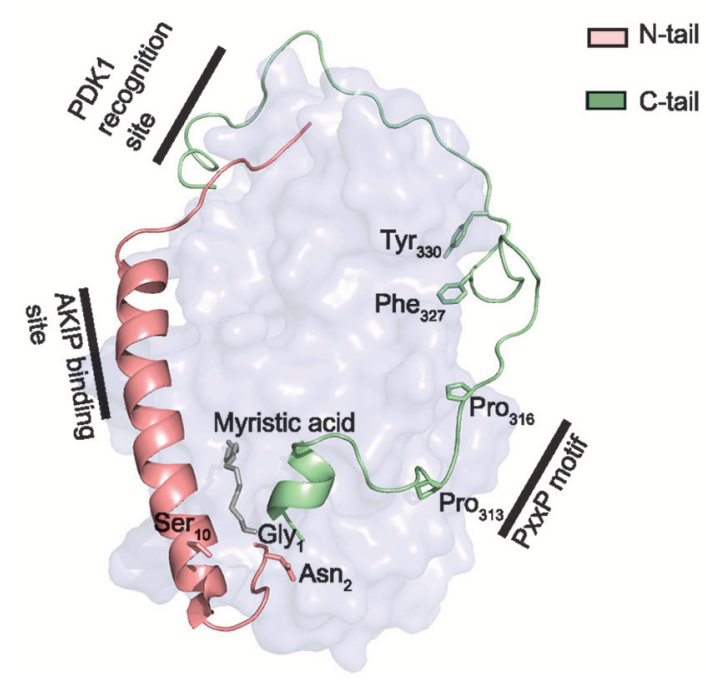

FIGURE 4 | Core and tail structures of the PKA C subunit. (A) C- and $\mathrm{R}$-spines in $\mathrm{C} \alpha 1$. In the active conformation of kinases, the $\mathrm{C}$ - and $\mathrm{R}$-spines are assembled. In the case of PKA C $\alpha 1$, the residues constituting the C-spine (yellow) are Ala70, Val57, Leu173, Ile174, Leu172, Met128, Met231, and Leu227. The adenine nucleobase of ATP (slate stick presentation) is also part of the C-spine. The R-spine (red) consists of $\mathrm{C} \alpha 1$ residues Leu106, Leu95, Phe185, and Tyr164. One-letter aa abbreviations are used in the figure. Figure is based upon (175). PDB identifier 3FJQ (169). (B) Presentation of the conserved kinase core (rendered as a surface in slate) of $\mathrm{C} \alpha 1$, including the $\mathrm{N}$-tail (salmon) and C-tail (green) in cartoon presentations. Myristic acid (gray) is shown bound to the hydrophobic pocket. Selected structures and residues in the $\mathrm{N}$ - and $\mathrm{C}$-tails are highlighted and described in the text. PDB identifier $1 \mathrm{CMK}(73)$. and $\mathrm{C} \beta$. In fact, Gly1 and Asn2 have been identified even in the $\mathrm{C} 1$ homologs of the early branching metazoans Hydra vulgaris (sequence identifier XP_002163934.1) and Amphimedon queenslandica (sequence identifier XP_011405630.1). It is wellestablished that Gly1 may have a function in mammals through its modification of myristoylation by the enzyme NMT (74). We have suggested that $\mathrm{N}$-myristoylation of PKA $\mathrm{C}$ subunits is a feature found in all vertebrate $C \alpha 1 / C \beta 1$ subunits, and maybe even all metazoan C1 subunits in general (188). N-terminal myristoylation of proteins appears to be an ancient mechanism, with the common ancestor gene of NMT possibly arising in early eukaryotic cells (189).

Deamidation of the neutrally charged residue Asn2 is likely the only way of obtaining a negatively charged residue adjacent to myristoylated Gly1, since the presence of a negatively charged residue next to Gly1 inhibits N-myristoylation $(83,190)$. Thus, the conservation of Asn2 may serve as a means for achieving myristoylated Gly1 and also obtaining a negatively charged aa number 2 through later deamidation of Asn2 to Asp2. Negatively charged residues next to myristoylated residues may contribute to promote their association to membranes. Studies from our group support the proposed cooperative function of Gly1 and Asn2, being both highly conserved. The $\beta$-Aspartyl shift mechanism (83), i.e., deamidation of Asn into Asp, occurs especially in the case of Asn being followed by residues Gly, Ser, or Ala (82). Indeed, alignment reveals that position 3 of vertebrate $\mathrm{C} \alpha 1 / \mathrm{C} \beta 1$ subunits is either Ser, Ala, or Thr (188). Whether the rate of deamidation of Asn2 of isoforms such as $\mathrm{C} \beta 1$ of mouse, containing Thr3, is reduced (and as a consequence reduced phosphorylation of Ser10) has not been determined.

When exclusively studying vertebrate exon 1-1 encoded sequences except for lamprey, i.e., sequences after the $\mathrm{C}$ subunit gene duplication, six positions have been shown to be invariant (188). These are Gly1, Asn2, Lys8, Gly9, Glu11, and Ser14. Also, there is a high degree of conservation of similar aa properties among several of the positions that do vary among vertebrate $\mathrm{C} \alpha 1 / \mathrm{C} \beta 1$ sequences. For example, residue 7 is either Lys or Arg which are both basic aa's, and the residue at position 13 is always occupied by an acidic aa, either Glu or Asp. The function of some of these residues has already been proposed. $\mathrm{N}$-myristoylated proteins depend on an additional signal in order to associate with membranes. The basic residues in PKA $\mathrm{C} \alpha 1 / \mathrm{C} \beta 1$ position 7 and 8 may serve this function, through forming electrostatic interactions with acidic phospholipids in membranes (191). Moreover, this is in line with the general N-terminal myristoylation motif, (M)GNXXXXRR (189, 192). Ser14 is solvent exposed, and potential functions of this residue are not known. Glu11 faces into the molecule and forms a salt bridge with Lys292, and may therefore contribute to structural stability. Hence it is reasonable to propose that Gly9 is structurally important in order for the N-terminus to adopt the right conformation, i.e., through the absence of potentially destructive steric hindrances.

Moreover, Ser10 is not highly conserved among vertebrate $\mathrm{C} \alpha 1 / \mathrm{C} \beta 1$ homologs, despite its proposed role in regulation of myr-in/myr-out conformation (74). Aa position 10 has only been found to be Ser in mammalian $C \alpha 1$ and $C \beta 1$, in addition 

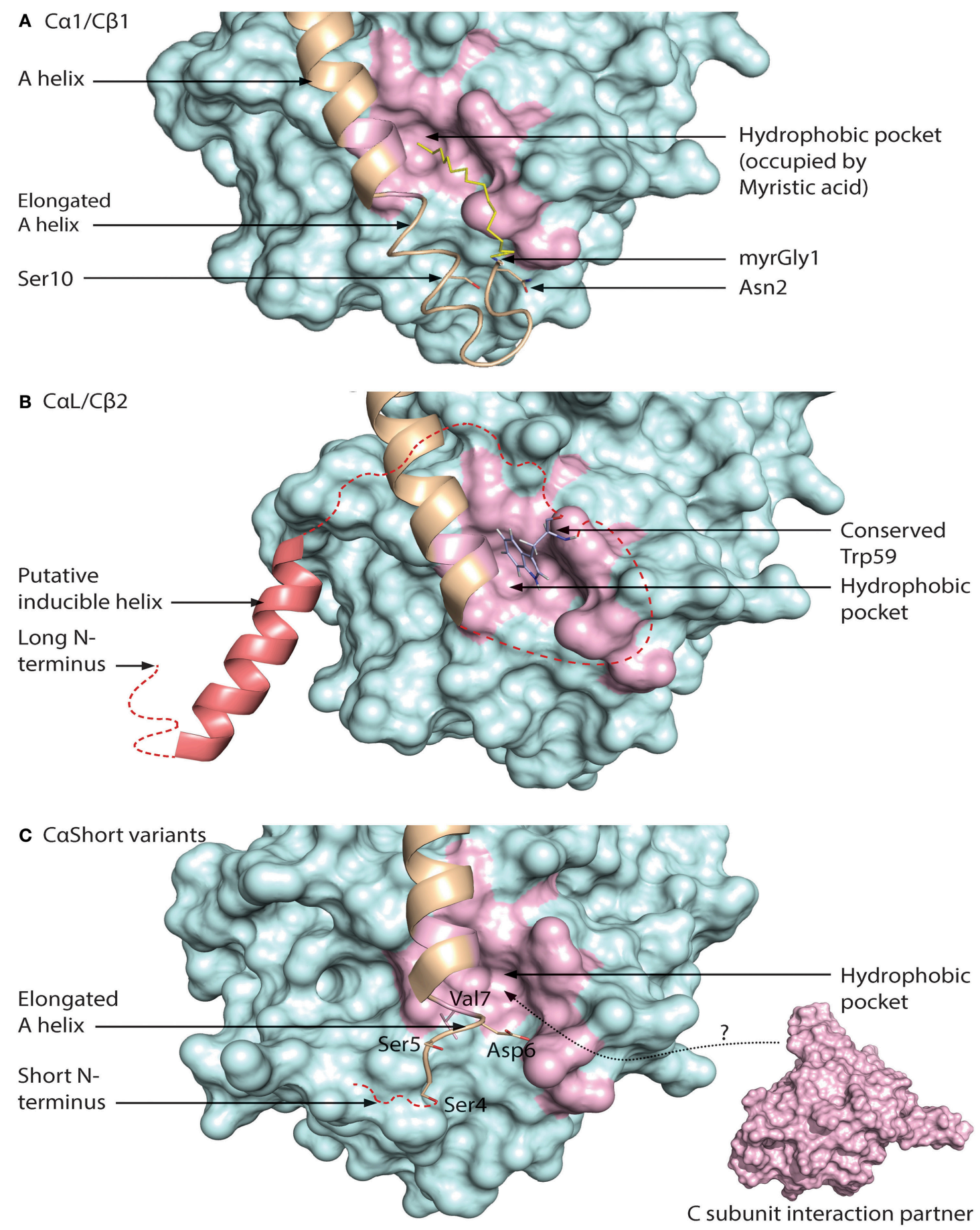

FIGURE 5 | Different configurations of $\mathrm{N}$ terminal parts of $\mathrm{C}$ subunit isoforms. For all figures, the $\mathrm{C}$ subunit is represented in cyan with the hydrophobic pocket highlighted in purple. Alternative exon 1 encoded parts of the $\mathrm{C}$ subunit are in orange cartoon presentation, in addition to the mainly exon 2 encoded $\mathrm{A}$ helix. Hypothesized (i.e., not supported by published crystal structure data) structures of $\mathrm{N}$-terminal residues are colored red. (A) Representation of human myristoylated C $\alpha 1$. The structure of unphosphorylated (Ser10), unmodified (i.e., not deamidated) Asn2, and Gly1-myristoylated Ca1 shows a fully ordered N-terminus. The modifiable residues in the $5^{\prime}$ encoded exon are highlighted in stick presentations, and myristic acid (yellow) occupies the hydrophobic pocket. Based on the structure with PDB identifier 1CMK (73). (B) Proposed model of $\mathrm{N}$-terminal structure of $\mathrm{C} \alpha \mathrm{L} / \mathrm{C} \beta 2$ homologs. Our study identified a conserved Trp59 (human $\mathrm{C} \beta 2$ numbering) (stick presentation, slate) residue which potentially occupies the hydrophobic pocket. The most conserved part of the $\mathrm{N}$-terminus was predicted to encode a helix structure, which we hypothesize may be ordered upon binding to interaction partners. The figure is modeled from the experimental structure of $\mathrm{C} \alpha 1$, with the $\mathrm{N}$-terminal residues encoded by exon 1 modeled. PDB identifier 1CMK (73). (C) Proposed model of N-terminal structure of C $\alpha$ Short variants. Short N-terminal transcripts in $\mathrm{C} \alpha$ were identified in most vertebrate species investigated. The short $\mathrm{N}$-terminal end displays the open hydrophobic pocket as earlier proposed for $\mathrm{C} \alpha 2$. The figure is based upon the experimental structure of human C $\alpha 2$ with PDB identifier 4AE9 (63). 
to selected amphibian and non-teleost fish $\mathrm{C} \alpha 1$ sequences. A more in depth analysis of different eutherian, i.e., placental mammalian, $C \alpha 1$ and $C \beta 1$ sequences from a range of species have revealed that Ser10 is conserved in all eutherian nucleotide sequences investigated. This may be interpreted as a possible case of convergent evolution of $\mathrm{C} \alpha 1$ and $C \beta 1$ proteins in and
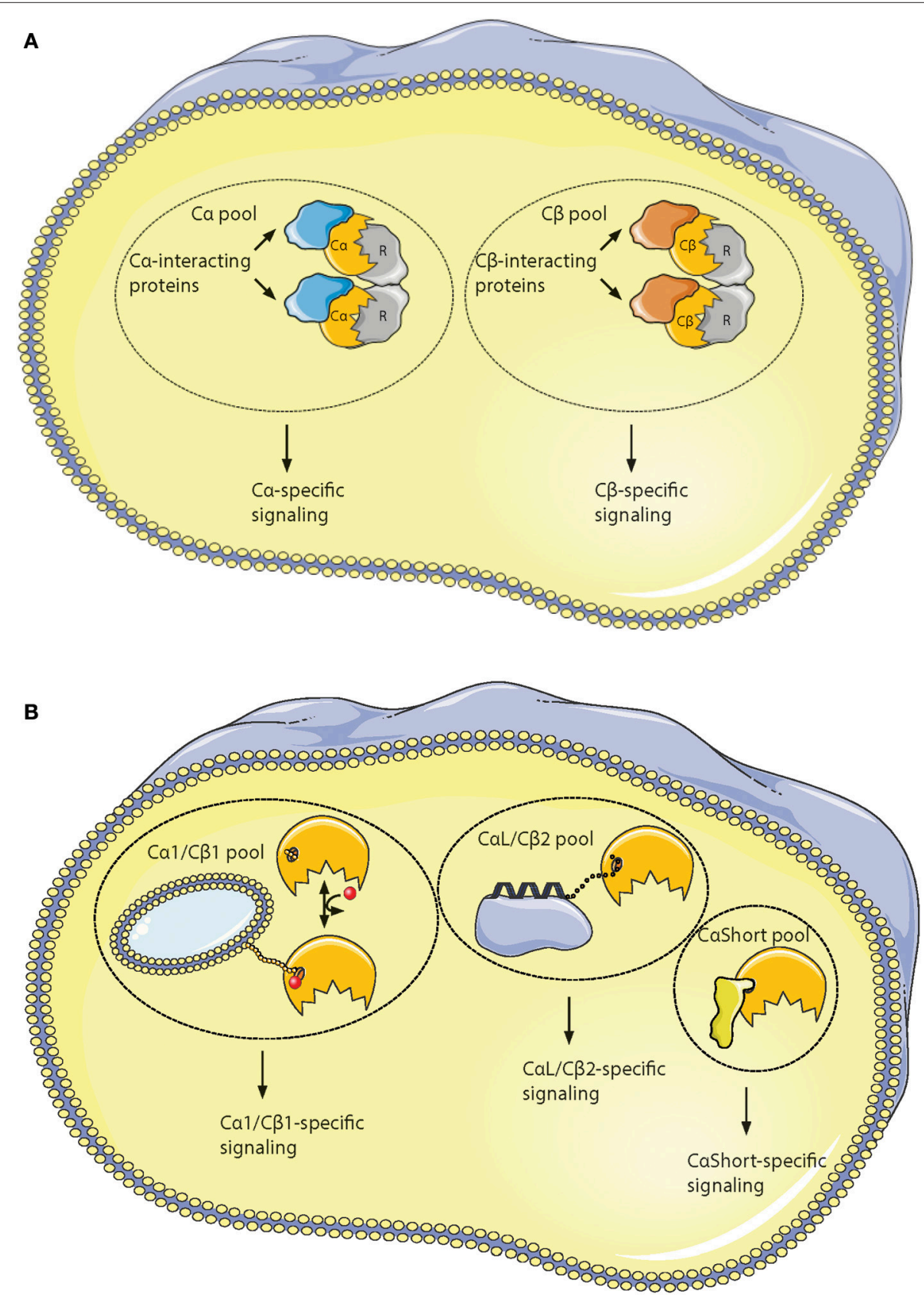

FIGURE 6 | Hypothesis of localized pools of isoform-specific PKA signaling. (A) Most of the variations in the Core $16-350$ residues in C $\alpha$ and C $\beta$ proteins are located to 11 solvent exposed residues in the small lobe. This opens for the possibility of $\mathrm{C} \alpha$ - and $\mathrm{C} \beta$-specific interaction partners interacting with the small lobe [described in (196)], possibly locating the two subunits into separate intracellular signaling pools. (B) Evolution of alternative N-termini in $\mathrm{C} \alpha$ and $\mathrm{C} \beta$ provides another mechanism for acquiring localized pools of isoform-specific PKA signaling [described in (188)]. The C $\alpha 1$ and C $\beta 1$ pool (left) shares the myristic acid with a regulatory mechanism, evolved in mammals, through phosphorylation/dephosphorylation of Ser10 for switching myristic acid in and out of the hydrophobic pocket (phosphate group presented as a red dot, and myristic acid presented as a yellow chain). This represents the main source of PKA C activity in most human cells. The conserved, putative inducible $\alpha$-helix opens for the possibility of a $\mathrm{C} \alpha \mathrm{L} / \mathrm{C} \beta 2$-specific pool (middle), docking the $\mathrm{C}$ subunits via a flexible linker to a C $\alpha\llcorner/ C \beta 2$-specific subcellular assembly of proteins (purple). The C $\alpha 2$ protein (CaShort pool, right) has a conserved sperm-specific expression in all mammals, and possibly interacts with C $\alpha 2$-specific proteins (bright yellow) binding to the hydrophobic pocket. Similar CaShort-specific proteins may exist in other tissues in non-mammals. Figure created using the Servier Medical Art resource (http://www.servier.com/Powerpoint-image-bank). 


\section{Evolved structure: $\quad$ Kinase group:}
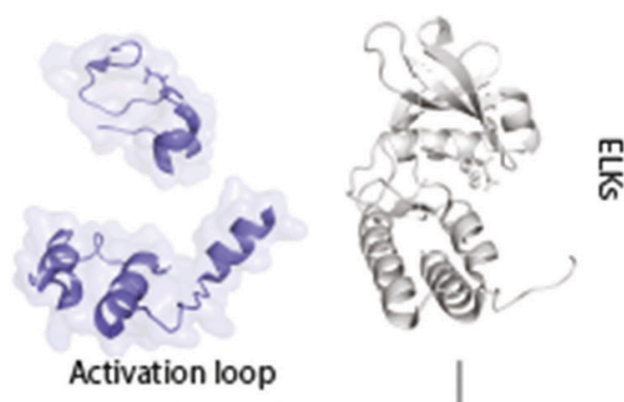

Activation loop
+
GHI domain

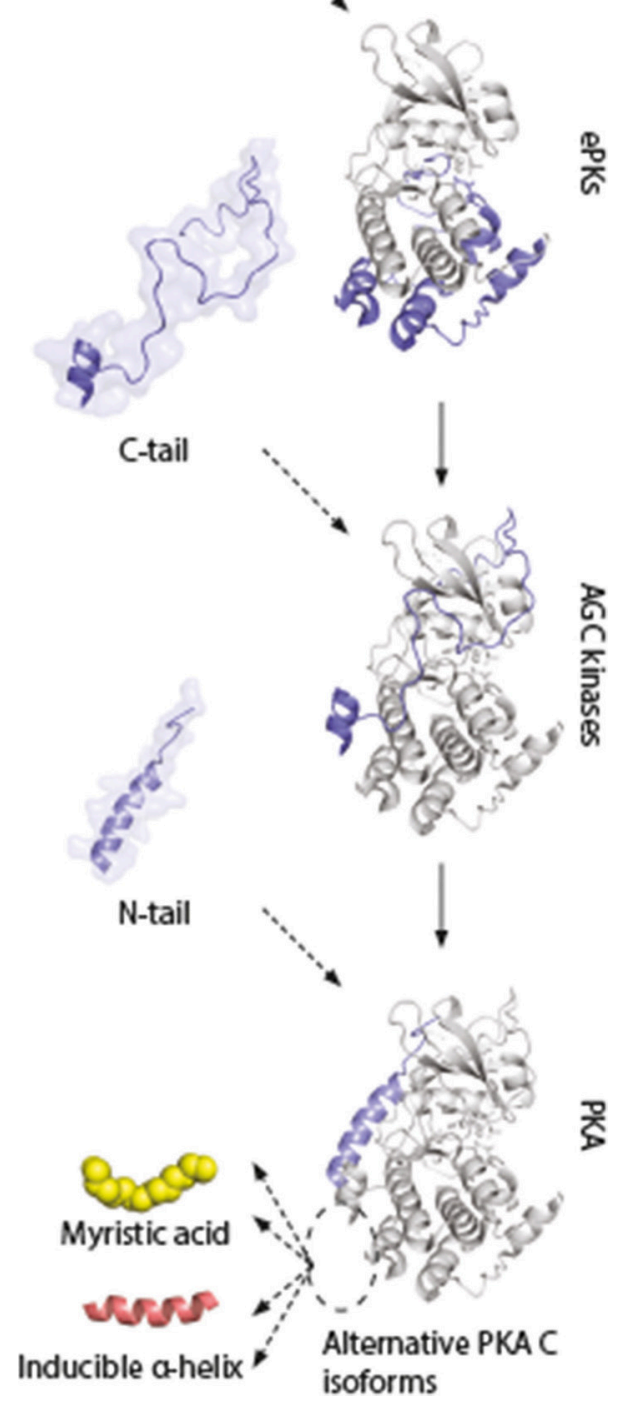

FIGURE 7 | Model of evolution of PKA C subunits. The catalytic core is a conserved feature of the eukaryotic-like kinases (ELKs). The ePKs differ from ELKs through the attainment of the activation loop, typically involving a phosphorylatable Thr which can regulate the catalytic core into active/inactive conformations, and the G, H, and I helices ("GHI domain"), serving as docking

(Continued)
FIGURE 7 | motifs for substrates (197). The C-tail is a conserved feature of the AGC group of ePKs, and is highly regulated and essential for catalytic activity (171). The $\mathrm{N}$-tail of PKA $\mathrm{C} \alpha$ and $\mathrm{C} \beta$ includes the $\mathrm{A}$ helix, which interacts with AKIP in C $\alpha 1$ residues 15-29 (128). This segment is shared among all C subunit isoforms, whereas the alternative $\mathrm{N}$-termini are located $\mathrm{N}$-terminal to the AKIP-docking site. These alterations give rise to possible functional effects in different C subunit isoforms ("myristic acid," "inducible helix," "..."). Figure inspired by Taylor et al. $(171,197)$. PDB, 3FJQ.

it may be speculated that Ser10 has an important function in $\mathrm{C} \alpha 1$ and $\mathrm{C} \beta 1$, possibly unique to mammals, and may involve the phosphorylation switch. Moreover, the fact that Ser10 is pointing into solution, it is therefore likely that it is highly solvent exposed.

To be noted all the vertebrate species where the PRKACA/PRKACB exon 1-1 do not encode Ser10 the residue at position 10 is always Gly in $\mathrm{C} \alpha$ and Asn 10 in $\mathrm{C} \beta$ (188). Due to the size and charge of Asn compared to Gly, this may further imply a larger fraction of $\mathrm{C} \beta$ in the myr-out conformation compared to $\mathrm{C} \alpha$. This may further imply that mammalian $\mathrm{C}$ subunits have acquired a post-translational method through evolution of regulating myr-conformation (through phosphorylation/dephosphorylation of Ser10). This also suggests that most other vertebrates only regulate this feature at the level of transcription through transcribing either PRKACA or PRKACB.

Recently, we also identified two positions that are consistently different in the mammalian $\mathrm{C} \alpha 1$ vs. $\mathrm{C} \beta 1 \mathrm{~N}$-terminus. Residue 5 is invariably Ala5 in $\mathrm{C} \alpha 1$ and Thr5 or Ile5 in $\mathrm{C} \beta 1$, whereas residue 12 is invariably Gln12 in $C \alpha 1$ and Val12 in $C \beta 1$. Gln12 is a more bulky and polar residue as opposed to the smaller and nonpolar aa Val12. Gln12 of $\mathrm{C} \alpha 1$ myr-in is oriented into the molecule, possibly stabilizing the $\mathrm{N}$-terminus. Thus, it may be suggested that Val12 of $C \beta 1$ makes the N-terminus more flexible and encourage the myr-out conformation. Alternatively, aa position 12 may serve other functions in the myr-out conformation, when it is solvent exposed and able to interact with other compounds. A model of $\mathrm{N}$-terminal features associated with the $\mathrm{C} \alpha 1$ and $C \beta 1$ proteins is shown in Figure 5A.

Exon 1-2 in PRKACB encodes 62 unique residues at the $\mathrm{N}$ terminal end of $C \beta 2$. Whereas $C \beta 2$ is identified in all major vertebrate groups, a paralogous PRKACA exon 1-L encoding a long $\mathrm{N}$-terminal $\mathrm{C} \alpha$ variant designated $\mathrm{C} \alpha \mathrm{L}$ has been identified at the mRNA level in all major vertebrate groups except for a likely loss in birds and mammals (188). The C $\alpha \mathrm{L} / \mathrm{C} \beta 2 \mathrm{~N}$ termini share several conserved features, by the fact that they firstly are all considerably longer than any other $5^{\prime}$ encoded exon variants of $P R K A C A$ and $P R K A C B$ identified. Secondly, the entire PRKACA/PRKACB exon 1-L/1-2 encoded N-termini have been predicted to be intrinsically disordered regions (IDRs). The identification of the $\mathrm{C} \alpha \mathrm{L} / \mathrm{C} \beta 2 \mathrm{~N}$-termini as putative IDRs does not exclude the possibility that they are containing regions that transiently become ordered and bind to other macromolecules. Wiemann et al. predicted the presence of an amphipathic helix in the N-terminus of $C \beta 2$ (67), and this putative $\alpha$-helix encoding region was the most conserved part of the $\mathrm{C} \alpha \mathrm{L} / \mathrm{C} \beta 2$ 
$\mathrm{N}$-terminus when the two sequences were aligned. In fact, using DISOPRED3 prediction (193) it may be suggested that this part may be protein binding. We propose that the putative IDRs of the $\mathrm{C} \alpha \mathrm{L} / \mathrm{C} \beta 2 \mathrm{~N}$-termini contain an inducible amphipathic $\alpha$ helix which is formed when interacting with so far unidentified $\mathrm{C} \alpha \mathrm{L}$-/C $\beta 2$-specific interaction partners (Figure 5B, "Putative inducible helix"). Flanking the predicted $\alpha$-helix are stretches of residues with less evolutionary pressure that are also predicted to be disordered. The segment spanning from the predicted $\alpha$ helix to the start of peptide sequence encoded by exon 2 may function as a flexible linker, analogous to a fishing line with the inducible $\alpha$-helix functioning as the "bait." In fact, putative, long (>30 residues) disordered segments occur in more than 30\% of eukaryotic proteins, and these proteins with IDRs are often involved in regulation of transcription and cell signaling (194). Coupled folding and binding provides a means for interactions of high specificity and relatively low affinity, which may be beneficial in signal transduction pathways, with the demand for transient signals and dissociation of proteins after a certain time (195).

Lacking the N-terminal Gly for myristoylation, we expect that the hydrophobic pocket of $\mathrm{C} \alpha \mathrm{L} / \mathrm{C} \beta 2$ is either empty or occupied by structures other than myristic acid. In $\mathrm{C} \beta 2$ we identified a conserved Trp59 (human C $\beta 2$ numbering) predicted to be located in proximity to the hydrophobic pocket (188). We speculate that Trp59 may function to occupy the entrance to the hydrophobic pocket, analogous to a lid, illustrated in Figure 5B (“Conserved Trp59").

We have also identified short exons, which were called exon 1-S, in PRKACA of all major vertebrate groups except the Coelacanth (188). In mammals, including marsupials and monotremes, this was demonstrated to be orthologs of the previously identified human sperm-specific Ca2 protein exon 1-2. Later we found that the sperm-specific expression pattern was also conserved in all mammals which suggests that $\mathrm{C} \alpha 2$ serves a role for male fertility not only in mice (65), but possibly in mammals in general. Whether or not exons 1-S of nonmammalian species are orthologs of mammalian 1-S (i.e., exon 1-2) was not possible to be verified, as described in Søberg et al. (188). Alignments of the C $\alpha 2$ proteins show low degree of conservation, and no obvious hydrophobic pocket-occupying properties. Purified human C $\alpha 2$ protein has been demonstrated to be able to bind hydrophobic moieties (63). We therefore suggest that $\mathrm{C} \alpha 2$, and possibly $\mathrm{C} \alpha \mathrm{S}$ in general, is conserved through its ability to associate with other proteins or structures binding to the hydrophobic pocket (Figure 5C).

\section{CONSERVED HETEROGENEITY IN PKA C SUBUNITS SUGGESTS ISOFORM-SPECIFIC SIGNALING POOLS}

It has been shown that all active $\mathrm{C} \alpha$ and $\mathrm{C} \beta$ splice variants are invariant in the core region encoded by PRKACA and PRKACB exons $2-10$, respectively (196). This spans the residues $16-$ 350 in $C \alpha 1$. However, residues distinguishing $\mathrm{C} \alpha$ from $C \beta$ are located to solvent-accessible loops in the small lobe as a signature motif distinguishing $\mathrm{C} \alpha$ from $\mathrm{C} \beta$ as paralogs. This together with the identification of key characteristics of the variable $\mathrm{N}$ terminal $\mathrm{C} \alpha$ and $\mathrm{C} \beta$ splice variants has made us suggest the existence of PKA isoform-specific signaling pools. We propose that $\mathrm{C} \alpha$ and $\mathrm{C} \beta$ proteins may associate with $\mathrm{C} \alpha$ - and $\mathrm{C} \beta$ specific C-KAPs, resulting in $\mathrm{C} \alpha$ - and $\mathrm{C} \beta$-specific downstream signaling (Figure 6A). Similarly, splice variant-specific pools may be achieved through alternative interaction partners binding to the heterogeneous $\mathrm{N}$-termini (Figure 6B).

This model supports the view of increased complexity and evolution into highly dynamic molecules in ePKs, where the conserved catalytic core contains most of the catalytic machinery necessary for enzymatic activity, whereas structures such as the $\mathrm{N}$ - and C-tails are involved in "fine-tuning" of PKA signaling through localization (197). This model also gives an understanding for why inactivation of kinase activity occurs when Gly186 is changed for a Val in C $\alpha$. This mutation is located in the highly conserved region of the kinase, shared among most PKs. The structures that are shared among all these kinases are typically important for catalysis. The evolved structures that build upon this framework (Figure 7, "activation loop," "GHI domain," "C-tail," and "N-tail") can be viewed as sophisticated modifications of PK structures, enabling a highly regulated $\mathrm{PK}$, both in terms of kinase activity and protein/membrane interactions. We suggest that the alternative PKA C isoforms represent an extension of this concept, and show the conservation of such alternative modifications located to the area around the hydrophobic pocket (Figure 7, dashed ellipse) and the small lobe. Similar increases in complexity in PKA signaling has been reported in other parts of the PKA signaling pathway, such as increases in R subunit and AKAP encoding genes throughout evolution $(198,199)$.

\section{ARE OFF-TARGET EFFECTS OF PKA C SUBUNIT ASSOCIATED WITH DISEASE?}

Evidence for the idea that targeting PKA C subunit activity in space and time is crucial for regulating PKA catalytic activity has emerged over the past decades. The first evidence for this was demonstrated in mice by Cummings and coworkers who showed that RI $\alpha$ compensation in RII $\beta$ null mutated was associated with dislocated PKA holoenzyme and increased basal PKA C subunit activity not regulated by cAMP due to lower affinity for the C subunit by RI $\alpha$ compared to RII $\beta$ (51). Additional support for this idea came from studies on RI $\alpha$ ablation in mice which is associated with severe developmental defects. Interestingly, the phenotype could be rescued by crossing the $\mathrm{RI} \alpha$ ablated mice with the $\mathrm{C} \alpha$ null mutated mice, suggesting that the phenotype is caused by abrogated regulation of $\mathrm{C}$ subunit activity (200). In man, the same research group also showed that haploinsufficiency at the PRKAR1A locus found in $\sim 75 \%$ of patients suffering from Carney complex (CNC), in addition to suffer from spotty skin pigmentation, cardiac and cutaneous myxomas, and endocrine tumors such as micronodular adrenocortical hyperplasia $(\mathrm{MAH})$, these proteins also had reduced fertility due to unregulated $\mathrm{C}$ subunit activity 
in male germ cells (201). Interestingly, Forlino and coworkers reported that a young woman (19 of age) who suffered from $\mathrm{CNC}$ and who had developed MAH carried a triplication of chromosome 1p31.1. Chromosome 1p31.1 contains the PRKACB gene which led the authors of this paper to suggest that this patient encoded increased levels of $\mathrm{C} \beta$. Based on this they further suggested that increased $\mathrm{C}$ subunit activity may be associated with disease pathogenesis and development of MAH (202).

Increased $\mathrm{C}$ subunit activity associated with disease pathogenesis is further supported by the identification of a frequent mutation in the PRKACA gene. The mutation Leu205Arg is located in the $\mathrm{P}+1$ loop of $\mathrm{C} \alpha 1$ but not $\mathrm{C} \beta 1$, rendering the $\mathrm{C}$ subunits insensitive to inhibition by the $\mathrm{R}$ subunits (203). This hotspot mutation was demonstrated to be the likely cause of nearly $70 \%$ of cortisol-producing adrenocortical adenomas (C-PAA) in Cushing patients (204). This finding was verified in a study by others (205).

Finally, two recent studies hamper the importance of locating C subunit activity. In fibrolamellar hepatocellular carcinoma (FLHCC), which is a rare liver tumor, a $\sim 400$-kilobase deletion on chromosome 19 leads to a chimeric gene product consisting of exon 1, also including parts of exon 2, of DNAJB1 fused with exon 2-10 of PRKACA (DNAJB1-PRKACA) $(206,207)$. The resulting DNAJB1-C $\alpha 1$ fusion protein retains $\mathrm{R}$ subunit binding capacity, and basal PKA C kinase activity in FL-HCC cell lysates is comparable that of lysates from normal liver cells.

\section{REFERENCES}

1. Scott JD, Pawson T. Cell signaling in space and time: where proteins come together and when they're apart. Science (2009) 326:1220-4. doi: 10.1126/science.1175668

2. Wong W, Scott JD. AKAP signalling complexes: focal points in space and time. Nat Rev Mol Cell Biol. (2004) 5:959-70. doi: 10.1038/nrm1527

3. Skålhegg BS, Taskén K. Specificity in the cAMP/PKA signaling pathway. Differential expression, regulation, and subcellular localization of subunits of PKA. Front Biosci. (2000) 5:678-93.

4. Zhang F, Zhang L, Qi Y, Xu H. Mitochondrial cAMP signaling. Cell Mol Life Sci. (2016) 73:4577-90. doi: 10.1007/s00018-016-2282-2

5. Hur EM, Kim KT. G protein-coupled receptor signalling and crosstalk: Achieving rapidity and specificity. Cell Signal. (2002) 14:397-405. doi: 10.1016/S0898-6568(01)00258-3

6. Liu Y, Yang Y, Ward R, An S, Guo XX, Li W, et al. Biased signalling: the instinctive skill of the cell in the selection of appropriate signalling pathways. Biochem J. (2015) 470:155-67. doi: 10.1042/BJ20150358

7. Villares Fragoso MC, Wanichi IQ, Cavalcante IP, Mariani BM. The role of GSP mutations on the development of adrenocortical tumors and adrenal hyperplasia. Front Endocrinol. (2016) 7:104. doi: 10.3389/fendo.2016.00104

8. Alberts B, Johnson A, Lewis J, Raff M, Roberts K, Walter P. Molecular Biology of the Cell, 4th edn. New York, NY: CRC Press (2002).

9. Distler M, Biel M, Flockerzi V, Hofmann F. Expression of cyclic nucleotidegated cation channels in non-sensory tissues and cells. Neuropharmacology (1994) 33:1275-82. doi: 10.1016/0028-3908(94)90027-2

10. Feng L, Subbaraya I, Yamamoto N, Baehr W, Kraus-Friedmann N. Expression of photoreceptor cyclic nucleotide-gated cation channel subunit (CNGCalpha) in the liver and skeletal muscle. FEBS Lett. (1996) 395:77-81. doi: 10.1016/0014-5793(96)01011-3

11. Finn JT, Grunwald ME, Yau KW. Cyclic nucleotied-gated ion channels: an extended family with diverse functions. Annu Rev Physiol. (1996) 58:395426. doi: 10.1146/annurev.ph.58.030196.002143
However, DNAJB1-C $\alpha$ has a reduced avidity for R subunits, and catalytic activity is greatly increased upon cAMP stimulation compared to WT $\mathrm{C} \alpha$ (29). In addition, the fusion transcript is expressed 10-fold higher than PRKACA (29). Moreover, the fusion protein interacts with $\beta$-catenin, and overexpression of WT C $\alpha$ does not fully recapitulate the oncogenic activity of DNAJB1-C $\alpha 1$. The latter may suggest that the pathogenesis of FL-HCC is not only dependent on altered PKA C activity but also on localization (208). Taken together these reports provide evidence that gain of function of $\mathrm{C} \alpha$ and $\mathrm{C} \beta$, respectively, provide two non-identical phenotypes (MAH and C-PAA) suggesting non-redundant functions. In addition, dislocation of PKA C subunits leads to off-target effects which are associated with disease.

\section{AUTHOR CONTRIBUTIONS}

KS has in collaboration with BS written and carefully revised the draft for this review. KS has in collaboration made the drafts and final layout of the figures.

\section{FUNDING}

This work was supported by the University of Oslo BS (2015/2017) and Throne Holst Foundation (2015/2017). Principal funding recipient was BS.

12. Podda MV, Grassi C. New perspectives in cyclic nucleotidemediated functions in the CNS: the emerging role of cyclic nucleotide-gated (CNG) channels. Pflugers Arch. (2014) 466:1241-57. doi: 10.1007/s00424-013-1373-2

13. Zufall F, Shepherd GM, Barnstable CJ. Cyclic nucleotide gated channels as regulators of CNS development and plasticity. Curr Opin Neurobiol. (1997) 7:404-12. doi: 10.1016/S0959-4388(97)80070-0

14. Bradley J, Reisert J, Frings S. Regulation of cyclic nucleotide-gated channels. Curr Opin Neurobiol. (2005) 15:343-9. doi: 10.1016/j.conb.2005.05.014

15. Cheng X, Ji Z, Tsalkova T, Mei F. Epac and PKA: a tale of two intracellular cAMP receptors. Acta Biochim Biophys Sin (Shanghai) (2008) 40:651-62. doi: 10.1111/j.1745-7270.2008.00438.x

16. Fujita T, Umemura M, Yokoyama U, Okumura S, Ishikawa Y. The role of Epac in the heart. Cell Mol Life Sci. (2016) 74:591-606. doi: 10.1007/s00018-016-2336-5

17. Lewis AE, Aesoy R, Bakke M. Role of EPAC in cAMP-mediated actions in adrenocortical Cells. Front Endocrinol (Lausanne) (2016) 7:63. doi: $10.3389 /$ fendo.2016.00063

18. Schindler RF, Scotton C, Zhang J, Passarelli C, Ortiz-Bonnin B, Simrick S, et al. POPDC1 ${ }^{S 201 F}$ causes muscular dystrophy and arrhythmia by affecting protein trafficking. J Clin Invest. (2016) 126:239-53. doi: 10.1172/JCI79562

19. Simrick S, Schindler RF, Poon KL, Brand T. Popeye domain-containing proteins and stress-mediated modulation of cardiac pacemaking. Trends Cardiovasc Med. (2013) 23:257-63. doi: 10.1016/j.tcm.2013.02.002

20. Zhang P, Smith-Nguyen EV, Keshwani MM, Deal MS, Kornev AP, Taylor SS. Structure and allostery of the PKA RII $\beta$ tetrameric holoenzyme. Science (2012) 335:712-6. doi: 10.1126/science.1213979

21. Greenwald EC, Saucerman JJ. Bigger, better, faster: principles and models of AKAP anchoring protein signaling. J Cardiovasc Pharmacol. (2011) 58:462-9. doi: 10.1097/FJC.0b013e31822001e3

22. Lehnart SE, Marks AR. Phosphodiesterase $4 \mathrm{D}$ and heart failure: a cautionary tale. Expert Opin Ther Targets (2006) 10:677-88. doi: $10.1517 / 14728222.10 .5 .677$ 
23. Dostmann WR, Taylor SS. Identifying the molecular switches that determine whether (Rp)-cAMPS functions as an antagonist or an agonist in the activation of cAMP-dependent protein kinase, I. Biochemistry (1991) 30:8710-6. doi: 10.1021/bi00099a032

24. Taskén K, Skålhegg BS, Taskén KA, Solberg R, Knutsen HK, Levy FO, et al. Structure, function, and regulation of human cAMP-dependent protein kinases. Adv Second Messenger Phosphoprotein Res. (1997) 31:191-204. doi: 10.1016/S1040-7952(97)80019-5

25. Øgreid D, Ekanger R, Suva RH, Miller JP, Sturm P, Corbin JD, et al. Activation of protein kinase isozymes by cyclic nucleotide analogs used singly or in combination. Principles for optimizing the isozyme specificity of analog combinations. Eur J Biochem. (1985) 150:219-27. doi: 10.1111/j.1432-1033.1985.tb09010.x

26. Corbin JD, Keely SL, Park CR. The distribution and dissociation of cyclic adenosine 3':5'-monophosphate-dependent protein kinases in adipose, cardiac, and other tissues. J Biol Chem. (1975) 250:218-25.

27. Døskeland SO, Øgreid D. Binding proteins for cyclic amp in mammalian tissues. Int J Biochem. (1981) 13:1-19. doi: 10.1016/0020-711X(81)90131-2

28. Carnegie GK, Means CK, Scott JD. A-kinase anchoring proteins: from protein complexes to physiology and disease. IUBMB Life (2009) 61:394-406. doi: 10.1002/iub.168

29. Riggle KM, Riehle KJ, Kenerson HL, Turnham R, Homma MK, Kazami $\mathrm{M}$, et al. Enhanced cAMP-stimulated protein kinase A activity in human fibrolamellar hepatocellular carcinoma. Pediatr Res. (2016) 80:110-8. doi: $10.1038 /$ pr.2016.36

30. Scott JD, Stofko RE, McDonald JR, Comer JD, Vitalis EA, Mangili JA. Type II regulatory subunit dimerization determines the subcellular localization of the cAMP-dependent protein kinase. J Biol Chem. (1990) 265:21561-6.

31. Wu J, Brown SH, von DS, Taylor SS. PKA Type IIalpha holoenzyme reveals a combinatorial strategy for isoform diversity. Science (2007) 318:274-9. doi: 10.1126/science.1146447

32. Carlson CR, Ruppelt A, Tasken K. A Kinase anchoring protein (AKAP) interaction and dimerization of the RIalpha and RIbeta Regulatory Subunits of Protein Kinase A in vivo by the yeast two hybrid system. J Mol Biol. (2003) 327:609-18. doi: 10.1016/S0022-2836(03)00093-7

33. Taskén K, Skålhegg BS, Solberg R, Andersson KB, Taylor SS, Lea T, et al. Novel isozymes of cAMP-dependent protein kinase exist in human cells due to formation of RI $\alpha$-RI $\beta$ heterodimeric complexes. J Biol Chem. (1993) 268:21276-83.

34. Autenrieth K, Bendzunas NG, Bertinetti D, Herberg FW, Kennedy EJ. Defining A-Kinase anchoring protein (AKAP) specificity for the protein kinase a subunit RI (PKA-RI). Chembiochem (2016) 17:693-7. doi: 10.1002/cbic. 201500632

35. Beene DL, Scott JD. A-kinase anchoring proteins take shape. Curr Opin Cell Biol. (2007) 19:192-8. doi: 10.1016/j.ceb.2007.02.011

36. Calejo AI, Taskén K. Targeting protein-protein interactions in complexes organized by a kinase anchoring proteins. Front Pharmacol. (2015) 6:192. doi: 10.3389/fphar.2015.00192

37. Zhang P, Kornev AP, Wu J, Taylor SS. Discovery of allostery in PKA signaling. Biophys Rev. (2015) 7:227-38. doi: 10.1007/s12551-015-0170-x

38. Anand GS, Hotchko M, Brown SH, Ten Eyck LF, Komives EA, Taylor SS. R-subunit isoform specificity in protein kinase a: distinct features of protein interfaces in PKA Types I and II by Amide $\mathrm{H} /{ }^{2} \mathrm{H}$ exchange mass spectrometry. J Mol Biol. (2007) 374:487-99. doi: 10.1016/j.jmb.2007.09.035

39. Su Y, Dostmann WR, Herberg FW, Durick K, Xuong NH, Ten EL, et al. Regulatory subunit of protein kinase A: structure of deletion mutant with cAMP binding domains. Science (1995) 269:807-13. doi: $10.1126 /$ science. 7638597

40. Clegg $\mathrm{CH}$, Cadd GG, McKnight GS. Genetic characterization of a brain-specific form of the type I regulatory subunit of cAMPdependent protein kinase. Proc Natl Acad Sci USA. (1988) 85:3703-7. doi: 10.1073/pnas.85.11.3703

41. Lee DC, Carmichael DF, Krebs EG, McKnight GS. Isolation of a cDNA clone for the type I regulatory subunit of bovine cAMP-dependent protein kinase. Proc Natl Acad Sci USA. (1983) 80:3608-12. doi: 10.1073/pnas.80. 12.3608

42. Scott JD, Glaccum MB, Zoller MJ, Uhler MD, Helfman DM, McKnight GS, et al. The molecular cloning of a type II regulatory subunit of the
cAMP-dependent protein kinase from rat skeletal muscle and mouse brain. Proc Natl Acad Sci USA. (1987) 84:5192-6. doi: 10.1073/pnas.84.15.5192

43. Cadd G, McKnight GS. Distinct patterns of cAMP-dependent protein kinase gene expression in mouse brain. Neuron (1989) 3:71-9. doi: 10.1016/0896-6273(89)90116-5

44. Jahnsen T, Hedin L, Kidd VJ, Beattie WG, Lohmann SM, Walter U, et al. Molecular cloning, cDNA structure, and regulation of the regulatory subunit of Type II cAMP-dependent protein kinase from rat ovarian granulosa cells. J Biol Chem. (1986) 261:12352-61.

45. Amieux PS, Cummings DE, Motamed K, Brandon EP, Wailes LA, Le K, et al. Compensatory regulation of ri $\alpha$ protein levels in protein kinase a mutant mice. J Biol Chem. (1997) 272:3993-8. doi: 10.1074/jbc.272.7.3993

46. Rao Y, Fischer QS, Yang Y, McKnight GS, LaRue A, Daw NW. Reduced ocular dominance plasticity and long-term potentiation in the developing visual cortex of protein kinase A RII $\alpha$ mutant mice. Eur J Neurosci. (2004) 20:837-42. doi: 10.1111/j.1460-9568.2004.0 3499.x

47. Saloustros E, Salpea P, Qi CF, Gugliotti LA, Tsang K, Liu S, et al. Hematopoietic neoplasms in Prkar2a-deficient mice. J Exp Clin Cancer Res. (2015) 34:143. doi: 10.1186/s13046-015-0257-z

48. Malmberg AB, Brandon EP, Idzerda RL, Liu H, McKnight GS, Basbaum AI. Diminished inflammation and nociceptive pain with preservation of neuropathic pain in mice with a targeted mutation of the type i regulatory subunit of cAMP-dependent protein kinase. J Neurosci. (1997) 17:7462-70. doi: 10.1523/JNEUROSCI.17-19-07462.1997

49. Brandon EP, Zhuo M, Huang YY, Qi M, Gerhold KA, Burton KA, et al. Hippocampal long-term depression and depotentiation are defective in mice carrying a targeted disruption of the gene encoding the RI $\beta$ subunit of cAMP-dependent protein kinase. Proc Natl Acad Sci USA. (1995) 92:8851-5. doi: 10.1073/pnas.92.19.8851

50. Huang YY, Kandel ER, Varshavsky L, Brandon EP, Qi M, Idzerda RL, et al. A genetic test of the effects of mutations in PKA on mossy fiber LTP, and its relation to spatial and contextual learning. Cell (1995) 83:1211-22.

51. Cummings DE, Brandon EP, Planas JV, Motamed K, Idzerda RL, McKnight GS. Genetically lean mice result from targeted disruption of the RII $\beta$ subunit of protein kinase A. Nature (1996) 382:622-6. doi: 10.1038/382 $622 \mathrm{a} 0$

52. Planas JV, Cummings DE, Idzerda RL, McKnight GS. Mutation of the RII $\beta$ subunit of protein kinase A differentially affects lipolysis but not gene induction in white adipose tissue. J Biol Chem. (1999) 274:36281-7. doi: $10.1074 /$ jbc.274.51.36281

53. Schreyer SA, Cummings DE, McKnight GS, LeBoeuf RC. Mutation of the RII $\beta$ subunit of protein kinase A prevents diet-induced insulin resistance and dyslipidemia in mice. Diabetes (2001) 50:2555-62. doi: 10.2337/diabetes.50.11.2555

54. Brandon EP, Logue SF, Adams MR, Qi M, Sullivan SP, Matsumoto $\mathrm{AM}$, et al. Defective motor behavior and neural gene expression in RII $\beta$-protein kinase A mutant mice. J Neurosci. (1998) 18:3639-49. doi: 10.1523/JNEUROSCI.18-10-03639.1998

55. Enns LC, Pettan-Brewer C, Ladiges W. Protein kinase A is a target for aging and the aging heart. Aging (2010) 2:238-43. doi: 10.18632/aging.100138

56. Walker-Gray R, Stengel F, Gold MG. Mechanisms for restraining cAMPdependent protein kinase revealed by subunit quantitation and crosslinking approaches. Proc Natl Acad Sci USA. (2017) 114:10414-9. doi: 10.1073/pnas.1701782114

57. Beebe SJ, Øyen O, Sandberg M, Frøysa A, Hansson V, Jahnsen T. Molecular cloning of a tissue-specific protein kinase $(C \gamma)$ from human testis representing a third isoform for the catalytic subunit of cAMP-dependent protein kinase. Mol Endocrinol. (1990) 4:465-75. doi: 10.1210/mend-4-3-465

58. Huang S, Li Q, Alberts I, Li X. PRKX, a novel cAMP-dependent protein kinase member, plays an important role in development. J Cell Biochem. (2016) 117:566-73. doi: 10.1002/jcb.25304

59. Reinton N, Haugen TB, Ørstavik S, Skålhegg BS, Hansson V, Jahnsen T, et al. The gene encoding the $\mathrm{C} \gamma$ catalytic subunit of cAMP-dependent protein kinase is a transcribed retroposon. Genomics (1998) 49:290-7. doi: 10.1006/geno.1998.5240

60. Schiebel K, Winkelmann M, Mertz A, Xu X, Page DC, Weil D, et al. Abnormal XY interchange between a novel isolated protein kinase 
gene, $P R K Y$, and its homologue, PRKX, accounts for one third of all (Y+)XX males and (Y-)XY females. Hum Mol Genet. (1997) 6:1985-9. doi: $10.1093 / \mathrm{hmg} / 6.11 .1985$

61. Zimmermann B, Chiorini JA, Ma Y, Kotin RM, Herberg FW. PrKX is a novel catalytic subunit of the cAMP-dependent protein kinase regulated by the regulatory subunit type, I. J Biol Chem. (1999) 274:5370-8. doi: $10.1074 /$ jbc. 274.9 .5370

62. Skålhegg BS, Huang Y, Su T, Idzerda RL, McKnight GS, Burton KA. Mutation of the $\mathrm{C} \alpha$ subunit of PKA leads to growth retardation and sperm dysfunction. Mol Endocrinol. (2002) 16:630-9. doi: 10.1210/mend.16.3.0793

63. Hereng TH, Backe PH, Kahmann J, Scheich C, Bjøras M, Skålhegg BS, et al. Structure and function of the human sperm-specific isoform of protein kinase A (PKA) catalytic subunit Ca2. J Struct Biol. (2012) 178:300-10. doi: $10.1016 /$ j.jsb.2012.03.013

64. Uhler MD, Chrivia JC, McKnight GS. Evidence for a second isoform of the catalytic Subunit of cAMP-dependent protein kinase. J Biol Chem. (1986) 261:15360-3.

65. Nolan MA, Babcock DF, Wennemuth G, Brown W, Burton KA, McKnight GS. Sperm-specific protein kinase A catalytic subunit $\mathrm{C}_{2}$ orchestrates cAMP signaling for male fertility. Proc Natl Acad Sci USA. (2004) 101:134838. doi: $10.1073 /$ pnas. 0405580101

66. Guthrie CR, Skålhegg BS, McKnight GS. Two novel brain-specific splice variants of the murine $\mathrm{C} \beta$ gene of cAMP-dependent protein kinase. J Biol Chem. (1997) 272:29560-5. doi: 10.1074/jbc.272.47.29560

67. Wiemann S, Kinzel V, Pyerin W. Isoform $C \beta_{2}$, an unusual form of the bovine catalytic subunit of cAMP-dependent protein kinase. J Biol Chem. (1991) 266:5140-6.

68. Kvissel AK, Ørstavik S, Øistad P, Rootwelt T, Jahnsen T, Skålhegg BS. Induction of $C \beta$ splice variants and formation of novel forms of protein kinase A type II holoenzymes during retinoic acid-induced differentiation of human NT2 cells. Cell Signal. (2004) 16:577-87. doi: 10.1016/j.cellsig.2003.08.014

69. Ørstavik S, Reinton N, Frengen E, Langeland BT, Jahnsen T, Skålhegg BS. Identification of novel splice variants of the human catalytic subunit $c \beta$ of cAMP-dependent protein kinase. Eur J Biochem. (2001) 268:5066-73. doi: 10.1046/j.0014-2956.2001.02429.x

70. Larsen AC, Kvissel AK, Hafte TT, Avellan CI, Eikvar S, Rootwelt T, et al. Inactive forms of the catalytic subunit of protein kinase $\mathrm{A}$ are expressed in the brain of higher primates. FEBS J. (2008) 275:250-62. doi: 10.1111/j.1742-4658.2007.06195.x

71. Breitenlechner C, Engh RA, Huber R, Kinzel V, Bossemeyer D, Gassel M. The typically disordered N-terminus of pka can fold as a helix and project the myristoylation site into solution. Biochemistry (2004) 43:7743-9. doi: $10.1021 /$ bi0362525

72. Cembran A, Masterson LR, McClendon CL, Taylor SS, Gao J, Veglia G. Conformational equilibrium of N-myristoylated cAMP-dependent protein kinase A by molecular dynamics simulations. Biochemistry (2012) 51:1018696. doi: 10.1021/bi301279f

73. Zheng J, Knighton DR, Xuong NH, Taylor SS, Sowadski JM, Ten Eyck LF. Crystal structures of the myristylated catalytic subunit of cAMP-dependent protein kinase reveal open and closed conformations. Protein Sci. (1993) 2:1559-73. doi: 10.1002/pro.5560021003

74. Gaffarogullari EC, Masterson LR, Metcalfe EE, Traaseth NJ, Balatri E, Musa MM, et al. A myristoyl/phosphoserine switch controls cAMP-Dependent protein kinase association to membranes. J Mol Biol. (2011) 411:823-36. doi: 10.1016/j.jmb.2011.06.034

75. Sastri M, Barraclough DM, Carmichael PT, Taylor SS. A-kinase-interacting protein localizes protein kinase A in the nucleus. Proc Natl Acad Sci USA. (2005) 102:349-54. doi: 10.1073/pnas.0408608102

76. Gangal M, Clifford T, Deich J, Cheng X, Taylor SS, Johnson DA. Mobilization of the A-kinase $N$-myristate through an isoform-specific intermolecular switch. Proc Natl Acad Sci USA. (1999) 96:12394-9. doi: 10.1073/pnas.96.22.12394

77. Zhang P, Ye F, Bastidas AC, Kornev AP, Wu J, Ginsberg MH, et al. An isoform-specific myristylation switch targets type II PKA holoenzymes to membranes. Structure. (2015) 23:1563-72. doi: 10.1016/j.str.2015.07.007

78. Tillo SE, Xiong WH, Takahashi M, Miao S, Andrade AL, Fortin DA, et al. Liberated PKA catalytic subunits associate with the membrane via myristoylation to preferentially phosphorylate membrane substrates. Cell Rep. (2017) 19:617-29. doi: 10.1016/j.celrep.2017.03.070

79. Gesellchen F, Bertinetti O, Herberg FW. Analysis of posttranslational modifications exemplified using protein kinase A. Biochim Biophys Acta (2006) 1764:1788-800. doi: 10.1016/j.bbapap.2006.10.001

80. Toner-Webb J, van Patten SM, Walsh DA, Taylor SS. Autophosphorylation of the catalytic subunit of cAMP-dependent protein kinase. J Biol Chem. (1992) 267:25174-80.

81. Pepperkok R, Hotz-Wagenblatt A, König N, Girod A, Bossemeyer D, Kinzel $\mathrm{V}$. Intracellular distribution of mammalian protein kinase A catalytic subunit altered by conserved Asn2 deamidation. J Cell Biol (2000) 148:715-26. doi: $10.1083 /$ jcb.148.4.715

82. Wright HT. Sequence and structure determinants of the nonenzymatic deamidation of asparagine and glutamine residues in proteins. Protein Eng. (1991) 4:283-94. doi: 10.1093/protein/4.3.283

83. Jedrzejewski PT, Girod A, Tholey A, König N, Thullner S, Kinzel V, et al. A conserved deamidation site at Asn 2 in the catalytic subunit of mammalian cAMP-dependent protein kinase detected by capillary LC-MS and tandem mass spectrometry. Protein Sci. (1998) 7:457-69. doi: 10.1002/pro.5560070227

84. Gamm DM, Baude EJ, Uhler MD. The major catalytic subunit isoforms of cAMP-dependent protein kinase have distinct biochemical properties in vitro and in vivo. J Biol Chem. (1996) 271:15736-42. doi: 10.1074/jbc.271.26.15736

85. Taylor SS, Kim C, Cheng CY, Brown SH, Wu J, Kannan N. Signaling through cAMP and cAMP-dependent protein kinase: diverse strategies for drug design. Biochim Biophys Acta (2008) 1784:16-26. doi: 10.1016/j.bbapap.2007.10.002

86. Funderud A, Aas-Hanssen K, Aksaas AK, Hafte TT, Corthay A, Munthe LA, et al. Isoform-specific regulation of immune cell reactivity by the catalytic subunit of protein kinase A (PKA). Cell Signal. (2009) 21:274-81. doi: 10.1016/j.cellsig.2008.10.013

87. Susuki-Miyata S, Miyata M, Lee BC, Xu H, Kai H, Yan C, et al. Crosstalk between PKA-C $\beta$ and $\mathrm{p} 65$ mediates synergistic induction of PDE4B by roflumilast and NTHi. Proc Natl Acad Sci USA. (2015) 112:1800-9. doi: $10.1073 /$ pnas. 1418716112

88. Brunton LL, Hayes JS, Mayer SE. Hormonally specific phosphorylation of cardiac troponin I and activation of glycogen phosphorylase. Nature (1979) 280:78-80. doi: $10.1038 / 280078 \mathrm{a} 0$

89. Corbin JD, Sugden PH, Lincoln TM, Keely SL. Compartmentalization of adenosine 3':5'-monophosphate and adenosine 3':5'-monophosphatedependent protein kinase in heart tissue. J Biol Chem. (1977) 252:3854-61.

90. Hayes JS, Brunton LL, Brown JH, Reese JB, Mayer SE. Hormonally specific expression of cardiac protein kinase activity. Proc Natl Acad Sci USA. (1979) 76:1570-4. doi: 10.1073/pnas.76.4.1570

91. Hayes JS, Brunton LL, Mayer SE. Selective activation of particulate cAMPdependent protein kinase by isoproterenol and prostaglandin E1. J Biol Chem. (1980) 255:5113-9.

92. Jurevicius J, Fischmeister R. cAMP compartmentation is responsible for a local activation of cardiac $\mathrm{Ca} 2+$ channels by beta-adrenergic agonists. Proc Natl Acad Sci USA. (1996) 93:295-9. doi: 10.1073/pnas. 93.1.295

93. Zaccolo M. Use of chimeric fluorescent proteins and fluorescence resonance energy transfer to monitor cellular responses. Circ Res. (2004) 94:866-73. doi: 10.1161/01.RES.0000123825.83803.CD

94. Mongillo M, McSorley T, Evellin S, Sood A, Lissandron V, Terrin A, et al. Fluorescence resonance energy transfer-based analysis of cAMP dynamics in live neonatal rat cardiac myocytes reveals distinct functions of compartmentalized phosphodiesterases. Circ Res. (2004) 95:67-75. doi: 10.1161/01.RES.0000134629.84732.11

95. Dema A, Perets E, Schulz MS, Deák VA, Klussmann E. Pharmacological targeting of AKAP-directed compartmentalized cAMP signalling. Cell Signal. (2015) 27:2474-87. doi: 10.1016/j.cellsig.2015.09.008

96. Jarnæss E, Taskén K. Spatiotemporal control of cAMP signalling processes by anchored signalling complexes. Biochem Soc Trans. (2007) 35:931-7. doi: $10.1042 /$ BST0350931

97. Tasken K, Aandahl EM. Localized effects of cAMP mediated by distinct routes of protein kinase A. Physiol Rev. (2004) 84:137-67. doi: $10.1152 /$ physrev.00021.2003 
98. Carr DW, Stofko-Hahn RE, Fraser ID, Bishop SM, Acott TS, Brennan RG, et al. Interaction of the regulatory subunit (RII) of cAMP-dependent protein kinase with RII-anchoring proteins occurs through an amphipathic helix binding motif. J Biol Chem. (1991) 266:14188-92.

99. Welch EJ, Jones BW, Scott JD. Networking with AKAPs: contextdependent regulation of anchored enzymes. Mol Interv. (2010) 10:86-97. doi: 10.1124/mi.10.2.6

100. Jarnaess E, Ruppelt A, Stokka AJ, Lygren B, Scott JD, Tasken K. Dual specificity A-kinase anchoring proteins (AKAPs) contain an additional binding region that enhances targeting of protein kinase A type I. J Biol Chem. (2008) 283:33708-18. doi: 10.1074/jbc.M804807200

101. Appert-Collin A, Baisamy L, Diviani D. Regulation of g protein-coupled receptor signaling by a-kinase anchoring proteins. J Recept Signal Transduct Res. (2006) 26:631-46. doi: 10.1080/10799890600923211

102. Dessauer CW. Adenylyl cyclase-A-kinase anchoring protein complexes: the next dimension in cAMP signaling. Mol Pharmacol. (2009) 76:935-41. doi: 10.1124/mol.109.059345

103. Nijholt IM, Dolga AM, Ostroveanu A, Luiten PG, Schmidt M, Eisel UL. Neuronal AKAP150 coordinates PKA and Epacmediated PKB/Akt phosphorylation. Cell Signal. (2008) 20:1715-24. doi: 10.1016/j.cellsig.2008.05.001

104. Virshup DM, Shenolikar S. From promiscuity to precision: protein phosphatases get a makeover. Mol Cell (2009) 33:537-45. doi: 10.1016/j.molcel.2009.02.015

105. Houslay MD, Adams DR. Putting the lid on phosphodiesterase 4. Nat Biotechnol. (2010) 28:38-40. doi: 10.1038/nbt0110-38

106. Day ME, Gaietta GM, Sastri M, Koller A, Mackey MR, Scott JD, et al. Isoform-specific targeting of PKA to multivesicular bodies. J Cell Biol. (2011) 193:347-63. doi: 10.1083/jcb.201010034

107. Ashby CD, Walsh DA. Characterization of the interaction of a protein inhibitor with adenosine 3',5'-monophosphate-dependent protein kinases. I Interaction with the catalytic subunit of the protein kinase. J Biol Chem. (1972) 247:6637-42

108. Gamm DM, Uhler MD. Isoform-specific differences in the potencies of murine protein kinase inhibitors are due to nonconserved amino-terminal residues. J Biol Chem. (1995) 270:7227-32. doi: 10.1074/jbc.270.13.7227

109. Herberg FW, Doyle ML, Cox S, Taylor SS. Dissection of the nucleotide and metal-phosphate binding sites in cAMP-dependent protein kinase. Biochemistry (1999) 38:6352-60. doi: 10.1021/bi982672w

110. Vetter MM, Zenn HM, Méndez E, van den Boom H, Herberg FW, Skålhegg BS. The testis-specific C $\alpha 2$ subunit of PKA is kinetically indistinguishable from the common C $\alpha 1$ subunit of PKA. BMC Biochem. (2011) 12:40. doi: 10.1186/1471-2091-12-40

111. Beebe SJ, Salomonsky P, Jahnsen T, Li Y. The C gamma subunit is a unique isozyme of the cAMP-dependent protein kinase. J Biol Chem. (1992) 267:25505-12.

112. Wen W, Meinkoth JL, Tsien RY, Taylor SS. Identification of a signal for rapid export of proteins from the nucleus. Cell (1995) 82:463-73. doi: 10.1016/0092-8674(95)90435-2

113. Belyamani M, Gangolli EA, Idzerda RL. Reproductive function in protein kinase inhibitor-deficient mice. Mol Cell Biol. (2001) 21:3959-63. doi: 10.1128/MCB.21.12.3959-3963.2001

114. Gangolli EA, Belyamani M, Muchinsky S, Narula A, Burton KA, McKnight GS, et al. Deficient gene expression in protein kinase inhibitor alpha Null mutant mice. Mol Cell Biol. (2000) 20:3442-8. doi: 10.1128/MCB.20.10.3442-3448.2000

115. Butt E, Abel K, Krieger M, Palm D, Hoppe V, Hoppe J, et al. cAMP- and cGMP-dependent protein kinase phosphorylation sites of the focal adhesion vasodilator-stimulated phosphoprotein (VASP) in vitro and in intact human platelets. J Biol Chem. (1994) 269:14509-17.

116. Köhler K, Louvard D, Zahraoui A. Rab13 regulates PKA signaling during tight junction assembly. J Cell Biol. (2004) 165:175-80. doi: $10.1083 /$ jcb. 200312118

117. Anderson RG. The caveolae membrane system. Annu Rev Biochem. (1998) 67:199-225. doi: 10.1146/annurev.biochem.67.1.199

118. Razani B, Lisanti MP. Two distinct caveolin-1 domains mediate the functional interaction of caveolin-1 with protein kinase A. Am J
Physiol Cell Physiol. (2001) 281:1241-50. doi: 10.1152/ajpcell.2001.281.4. C1241

119. Cohen AW, Razani B, Schubert W, Williams TM, Wang XB, Iyengar $\mathrm{P}$, et al. Role of caveolin-1 in the modulation of lipolysis and lipid droplet formation. Diabetes (2004) 53:1261-70. doi: 10.2337/diabetes.53. 5.1261

120. Brasaemle DL. Thematic review series: adipocyte biology. The perilipin family of structural lipid droplet proteins: stabilization of lipid droplets and control of lipolysis. J Lipid Res. (2007) 48:2547-59. doi: 10.1194/jlr.R700014-JLR200

121. Pidoux G, Witczak O, Jarnaess E, Myrvold L, Urlaub H, Stokka AJ, et al. Optic atrophy 1 is an A-kinase anchoring protein on lipid droplets that mediates adrenergic control of lipolysis. EMBO J. (2011) 30:4371-86. doi: 10.1038/emboj.2011.365

122. Higuchi H, Yamashita T, Yoshikawa H, Tohyama M. PKA phosphorylates the p75 receptor and regulates its localization to lipid rafts. EMBO J. (2003) 22:1790-800. doi: 10.1093/emboj/cdg177

123. Bilderback TR, Grigsby RJ, Dobrowsky RT. Association of p75(NTR) with caveolin and localization of neurotrophin-induced sphingomyelin hydrolysis to caveolae. J Biol Chem. (1997) 272:10922-7. doi: 10.1074/jbc.272.16.10922

124. Gentry JJ, Barker PA, Carter BD. The p75 neurotrophin receptor: multiple interactors and numerous functions. Prog Brain Res. (2004) 146:25-39. doi: 10.1016/S0079-6123(03)46002-0

125. Ray BK, Chen J, Ray A. Catalytic subunit of protein kinase A is an interacting partner of the inflammation-responsive transcription factor serum amyloid A-activating factor-1. J Immunol. (2001) 167:2343-8. doi: 10.4049/jimmunol.167.4.2343

126. Ray A, Kumar D, Ray BK. Promoter-binding activity of inflammationresponsive transcription factor SAF is regulated by cyclic AMP signaling pathway. DNA Cell Biol. (2002) 21:31-40. doi: 10.1089/10445490252810294

127. Gao N, Asamitsu K, Hibi Y, Ueno T, Okamoto T. AKIP1 Enhances NF- $\kappa \mathrm{B}$-dependent gene expression by promoting the nuclear retention and phosphorylation of p65. J Biol Chem. (2008) 283:7834-43. doi: 10.1074/jbc.M710285200

128. King CC, Sastri M, Chang P, Pennypacker J, Taylor SS. The rate of NF-кB nuclear translocation is regulated by $\mathrm{PKA}$ and $\mathrm{A}$ kinase interacting protein 1. PLoS ONE (2011) 6:e18713. doi: 10.1371/journal.pone.0018713

129. Ghil S, Choi JM, Kim SS, Lee YD, Liao Y, Birnbaumer L, et al. Compartmentalization of protein kinase A signaling by the heterotrimeric $\mathrm{G}$ protein $\mathrm{G}_{\mathrm{o}}$. Proc Natl Acad Sci USA. (2006) 103:19158-63. doi: $10.1073 /$ pnas.0609392103

130. Bloom TJ, Beavo JA. Identification and tissue-specific expression of PDE7 phosphodiesterase splice variants. Proc Natl Acad Sci USA. (1996) 93:1418892. doi: $10.1073 /$ pnas.93.24.14188

131. Han P, Sonati P, Rubin C, Michaeli T. PDE7A1, a cAMP-specific phosphodiesterase, inhibits cAMP-dependent protein kinase by a direct interaction with C. J Biol Chem. (2006) 281:15050-7. doi: 10.1074/jbc.M601333200

132. Schillace RV, Andrews SF, Liberty GA, Davey MP, Carr DW. Identification and characterization of myeloid translocation gene $16 \mathrm{~b}$ as a novel a kinase anchoring protein in T lymphocytes. J Immunol. (2002) 168:1590-9. doi: 10.4049/jimmunol.168.4.1590

133. Fiedler SE, Schillace RV, Daniels CJ, Andrews SF, Carr DW. Myeloid translocation gene $16 \mathrm{~b}$ is a dual A-kinase anchoring protein that interacts selectively with plexins in a phospho-regulated manner. FEBS Lett. (2010) 584:873-7. doi: 10.1016/j.febslet.2010.02.007

134. Asirvatham AL, Galligan SG, Schillace RV, Davey MP, Vasta V, Beavo JA, et al. A-kinase anchoring proteins interact with phosphodiesterases in $\mathrm{T}$ lymphocyte cell lines. J Immunol. (2004) 173:4806-14. doi: 10.4049/jimmunol.173.8.4806

135. Roux PP, Blenis J. ERK and p38 MAPK-activated protein kinases: a family of protein kinases with diverse biological functions. Microbiol Mol Biol Rev. (2004) 68:320-44. doi: 10.1128/MMBR.68.2.320-344.2004

136. Chaturvedi D, Poppleton HM, Stringfield T, Barbier A, Patel TB. Subcellular localization and biological actions of activated RSK1 are determined by its interactions with subunits of cyclic AMP-dependent protein kinase. Mol Cell Biol. (2006) 26:4586-600. doi: 10.1128/MCB.01422-05 
137. Kostenko S, Shiryaev A, Dumitriu G, Gerits N, Moens U. Crosstalk between protein kinase $\mathrm{A}$ and the MAPK-activated protein kinases RSK1 and MK5. J Recept Signal Transduct Res. (2011) 31:1-9. doi: 10.3109/10799893.2010.515593

138. Chaturvedi D, Cohen MS, Taunton J, Patel TB. The PKARIalpha subunit of protein kinase A modulates the activation of p90RSK1 and its function. J Biol Chem. (2009) 284:23670-81. doi: 10.1074/jbc.M109.032813

139. Morimoto RI. Cells in stress: transcriptional activation of heat shock genes. Science (1993) 259:1409-10. doi: 10.1126/science.8451637

140. Xia W, Voellmy R. Hyperphosphorylation of heat shock transcription factor 1 is correlated with transcriptional competence and slow dissociation of active factor trimers. J Biol Chem. (1997) 272:4094-102. doi: 10.1074/jbc.272.7.4094

141. Xiao X, Zuo X, Davis AA, McMillan DR, Curry BB, Richardson JA, et al. HSF1 is required for extra-embryonic development, postnatal growth and protection during inflammatory responses in mice. EMBO J. (1999) 18:5943-52. doi: 10.1093/emboj/18.21.5943

142. Murshid A, Chou SD, Prince T, Zhang Y, Bharti A, Calderwood SK. Protein kinase A binds and activates heat shock factor 1. PLoS ONE (2010) 5:e13830. doi: 10.1371/journal.pone.0013830

143. Choi HS, Li B, Lin Z, Huang E, Liu AY. cAMP and cAMP-dependent protein kinase regulate the human heat shock protein 70 gene promoter activity. $J$ Biol Chem. (1991) 266:11858-65.

144. Kaghad M, Bonnet H, Yang A, Creancier L, Biscan JC, Valent A, et al. Monoallelically expressed gene related to p53 at 1p36, a region frequently deleted in neuroblastoma and other human cancers. Cell (1997) 90:809-19. doi: 10.1016/S0092-8674(00)80540-1

145. Hanamoto T, Ozaki T, Furuya K, Hosoda M, Hayashi S, Nakanishi M, et al. Identification of protein kinase A catalytic subunit $\beta$ as a novel binding partner of p73 and regulation of p73 function. J Biol Chem. (2005) 280:16665-75. doi: 10.1074/jbc.M414323200

146. Sample V, DiPilato LM, Yang JH, Ni Q, Saucerman JJ, Zhang J. Regulation of nuclear PKA revealed by spatiotemporal manipulation of cyclic AMP. Nat Chem Biol. (2012) 8:375-82. doi: 10.1038/nchembio.799

147. Ørstavik S, Eide T, Collas P, Han IO, Tasken K, Kieff E, et al. Identification, cloning and characterization of a novel nuclear protein, HA95, homologous to A-kinase anchoring protein 95. Biol Cell (2000) 92:27-37. doi: 10.1016/S0248-4900(00)88761-4

148. Westberg C, Yang JP, Tang H, Reddy TR, Wong-Staal F. A novel shuttle protein binds to RNA helicase A and activates the retroviral constitutive transport element. J Biol Chem. (2000) 275:21396-401. doi: 10.1074/jbc.M909887199

149. Martins SB, Eide T, Steen RL, Jahnsen T, Skalhegg BS, Collas P. HA95 is a protein of the chromatin and nuclear matrix regulating nuclear envelope dynamics. J Cell Sci. (2000) 113(Pt 21):3703-13.

150. Martins S, Eikvar S, Furukawa K, Collas P. HA95 and LAP2 beta mediate a novel chromatin-nuclear envelope interaction implicated in initiation of DNA replication. J Cell Biol. (2003) 160:177-88. doi: 10.1083/jcb.200210026

151. Li Y, Kao GD, Garcia BA, Shabanowitz J, Hunt DF, Qin J, et al. A novel histone deacetylase pathway regulates mitosis by modulating Aurora B kinase activity. Genes Dev. (2006) 20:2566-79. doi: 10.1101/gad.1455006

152. Han I, Harada S, Weaver D, Xue Y, Lane W, Orstavik S, et al. EBNA-LP associates with cellular proteins including DNA-PK and HA95. J Virol. (2001) 75:2475-81. doi: 10.1128/JVI.75.5.2475-2481.2001

153. Han I, Xue Y, Harada S, Orstavik S, Skalhegg B, Kieff E. Protein kinase A associates with HA95 and affects transcriptional coactivation by epstein-barr virus nuclear proteins. Mol Cell Biol. (2002) 22:2136-46. doi: 10.1128/MCB.22.7.2136-2146.2002

154. Tormanen PH, Aksaas AK, Kvissel AK, Punga T, Engstrom A, Skalhegg BS, et al. Two cellular protein kinases, DNA-PK and PKA, phosphorylate the adenoviral L4-33K protein and have opposite effects on L1 alternative RNA splicing. PLoS ONE (2012) 7:e31871. doi: 10.1371/journal.pone.00 31871

155. Kvissel AK, Tormanen PH, Aksaas AK, Akusjarvi G, Skalhegg BS. Regulation of Adenovirus Alternative RNA Splicing by PKA, DNA-PK, PP2A and SR Proteins (2014). p. 1-31.

156. Kvissel AK, Orstavik S, Eikvar S, Brede G, Jahnsen T, Collas P, et al. Involvement of the catalytic subunit of protein kinase $\mathrm{A}$ and of HA95 in pre-mRNA splicing. Exp Cell Res. (2007) 313:2795-809. doi: 10.1016/j.yexcr.2007.05.014

157. Long JC, Caceres JF. The SR protein family of splicing factors: master regulators of gene expression. Biochem J. (2009) 417:15-27. doi: 10.1042/BJ20081501

158. Fax P, Carlson CR, Collas P, Tasken K, Esche H, Brockmann D. Binding of PKA-RIIalpha to the Adenovirus E1A12S oncoprotein correlates with its nuclear translocation and an increase in PKA-dependent promoter activity. Virology (2001) 285:30-41. doi: 10.1006/viro.2001.0926

159. Aksaas AK, Eikvar S, Akusjarvi G, Skalhegg BS, Kvissel AK. Protein kinase a-dependent phosphorylation of serine 119 in the protooncogenic serine/arginine-rich splicing factor 1 modulates its activity as a splicing enhancer protein. Genes Cancer (2011) 2:841-51. doi: 10.1177/1947601911430226

160. Shi J, Qian W, Yin X, Iqbal K, Grundke-Iqbal I, Gu X, et al. Cyclic AMPdependent protein kinase regulates the alternative splicing of tau exon 10: a mechanism involved in tau pathology of Alzheimer disease. J Biol Chem. (2011) 286:14639-48. doi: 10.1074/jbc.M110.204453

161. Gu Q, Jin N, Sheng H, Yin X, Zhu J. Cyclic AMP-dependent protein kinase A regulates the alternative splicing of CaMKIIdelta. PLoS ONE (2011) 6:e25745. doi: 10.1371/journal.pone.0025745

162. Aksaas AK, Larsen AC, Rogne M, Rosendal K, Kvissel AK, Skålhegg BS. G-patch domain and KOW motifs-containing protein, GPKOW; a nuclear RNA-binding protein regulated by protein kinase A. J Mol Signal. (2011) 6:10. doi: 10.1186/1750-2187-6-10

163. Jin SL, Richard FJ, Kuo WP, D'Ercole AJ, Conti M. Impaired growth and fertility of cAMP-specific phosphodiesterase PDE4D-deficient mice. Proc Natl Acad Sci USA. (1999) 96:11998-2003. doi: 10.1073/pnas.96.21.11998

164. Kim C, Xuong NH, Taylor SS. Crystal structure of a complex between the catalytic and regulatory (RIalpha) subunits of PKA. Science (2005) 307:6906. doi: 10.1126/science.1104607

165. Levin AM, Coroneus JG, Cocco MJ, Weiss GA. Exploring the interaction between the protein kinase A catalytic subunit and caveolin-1 scaffolding domain with shotgun scanning, oligomer complementation, NMR, and docking. Protein Sci. (2006) 15:478-86. doi: 10.1110/ps.051911706

166. Moore MJ, Kanter JR, Jones KC, Taylor SS. Phosphorylation of the catalytic subunit of protein kinase A. Autophosphorylation versus phosphorylation by phosphoinositide-dependent kinase-1. J Biol Chem. (2002) 277:47878-84. doi: 10.1074/jbc.M204970200

167. Taylor SS, Kim C, Vigil D, Haste NM, Yang J, Wu J, et al. Dynamics of signaling by PKA. Biochim Biophys Acta (2005) 1754:25-37. doi: 10.1016/j.bbapap.2005.08.024

168. Hanks SK, Quinn AM, Hunter T. The protein kinase family: conserved features and deduced phylogeny of the catalytic domains. Science (1988) 241:42-52. doi: 10.1126/science.3291115

169. Thompson EE, Kornev AP, Kannan N, Kim C, Ten Eyck LF, Taylor SS. Comparative surface geometry of the protein kinase family. Protein Sci. (2009) 18:2016-26. doi: 10.1002/pro.209

170. Adams JA, Taylor SS. Divalent metal ions influence catalysis and activesite accessibility in the cAMP-dependent protein kinase. Protein Sci. (1993) 2:2177-86. doi: 10.1002/pro.5560021217

171. Taylor SS, Zhang P, Steichen JM, Keshwani MM, Kornev AP. PKA: lessons learned after twenty years. Biochim Biophys Acta (2013) 1834:1271-8. doi: 10.1016/j.bbapap.2013.03.007

172. Knighton DR, Zheng JH, Ten Eyck LF, Ashford VA, Xuong NH, Taylor SS, et al. Crystal structure of the catalytic subunit of cyclic adenosine monophosphate-dependent protein kinase. Science (1991) 253:407-14. doi: 10.1126/science.1862342

173. Zhang J, Yang PL, Gray NS. Targeting cancer with small molecule kinase inhibitors. Nat Rev Cancer (2009) 9:28-39. doi: 10.1038/nrc2559

174. Johnson DA, Akamine P, Radzio-Andzelm E, Madhusudan M, Taylor SS. Dynamics of cAMP-dependent protein kinase. Chem Rev. (2001) 101:224370. doi: $10.1021 / \mathrm{cr} 000226 \mathrm{k}$

175. Taylor SS, Kornev AP. Protein kinases: evolution of dynamic regulatory proteins. Trends Biochem Sci. (2011) 36:65-77. doi: 10.1016/j.tibs.2010.09.006

176. Torkamani A, Kannan N, Taylor SS, Schork NJ. Congenital disease SNPs target lineage specific structural elements in protein kinases. 
Proc Natl Acad Sci USA. (2008) 105:9011-6. doi: 10.1073/pnas.08024 03105

177. Zimmermann B, Schweinsberg S, Drewianka S, Herberg FW. Effect of metal ions on high-affinity binding of pseudosubstrate inhibitors to PKA. Biochem J. (2008) 413:93-101. doi: 10.1042/BJ20071665

178. Cook PF, Neville MEJr, Vrana KE, Hartl FT, Roskoski RJr. Adenosine cyclic 3',5'-monophosphate dependent protein kinase: kinetic mechanism for the bovine skeletal muscle catalytic subunit. Biochemistry (1982) 21:5794-9. doi: 10.1021/bi00266a011

179. Khavrutskii IV, Grant B, Taylor SS, McCammon JA. A Transition path ensemble study reveals a linchpin role for $\mathrm{Mg}^{2+}$ during rate-limiting ADP release from protein kinase, A. Biochemistry (2009) 48:11532-45. doi: $10.1021 /$ bi901475g

180. Shaffer J, Adams JA. An ATP-linked structural change in protein kinase A precedes phosphoryl transfer under physiological magnesium concentrations. Biochemistry (1999) 38:5572-81. doi: 10.1021/bi982768q

181. Jacobsen DM, Bao ZQ, O'Brien P, Brooks CLIII, Young MA. Price to be paid for two-metal catalysis: magnesium ions that accelerate chemistry unavoidably limit product release from a protein kinase. J Am Chem Soc. (2012) 134:15357-70. doi: 10.1021/ja304419t

182. Knape MJ, Ahuja LG, Bertinetti D, Burghardt NC, Zimmermann B, Taylor SS, et al. Divalent metal ions $\mathrm{Mg}^{2+}$ and $\mathrm{Ca}^{2+}$ have distinct effects on protein kinase A activity and regulation. ACS Chem Biol. (2015) 10:2303-15. doi: 10.1021/acschembio.5b00271

183. Søberg K, Larsen AC, Diskar M, Backe PH, Bjoras M, Jahnsen T, et al. Identification and characterization of novel mutations in the human gene encoding the catalytic subunit Calpha of protein kinase A (PKA). PLoS ONE (2012) 7:e34838. doi: 10.1371/journal.pone.0034838

184. Kornev AP, Haste NM, Taylor SS, Eyck LF. Surface comparison of active and inactive protein kinases identifies a conserved activation mechanism. Proc Natl Acad Sci USA. (2006) 103:17783-8. doi: 10.1073/pnas.0607656103

185. Kannan N, Haste N, Taylor SS, Neuwald AF. The hallmark of AGC kinase functional divergence is its C-terminal tail, a cis-acting regulatory module. Proc Natl Acad Sci USA. (2007) 104:1272-7. doi: 10.1073/pnas.0610251104

186. Kaneko T, Li L, Li SS. The SH3 domain- a family of versatile peptide- and protein-recognition module. Front Biosci. (2008) 13:3953. doi: 10.2741/3053

187. Tholey A, Pipkorn R, Bossemeyer D, Kinzel V, Reed J. Influence of myristoylation, phosphorylation, and deamidation on the structural behavior of the N-terminus of the catalytic subunit of CAMP-dependent protein kinase. Biochemistry (2001) 40:225-31. doi: 10.1021/bi0021277

188. Søberg K, Moen LV, Skalhegg BS, Laerdahl JK. Evolution of the cAMPdependent protein kinase (PKA) catalytic subunit isoforms. PLoS ONE (2017) 12:e0181091. doi: 10.1371/journal.pone.0181091

189. Dumonceaux T, Rajala RV, Sharma R, Selvaraj G, Datla R. Molecular characterization of a gene encoding $N$-myristoyl transferase (NMT) from Triticum aestivum (bread wheat). Genome (2004) 47:1036-42. doi: 10.1139/g04-074

190. Towler DA, Gordon JI, Adams SP, Glaser L. The biology and enzymology of eukaryotic protein acylation. Annu Rev Biochem. (1988) 57:69-99. doi: 10.1146/annurev.bi.57.070188.000441

191. Resh MD. Fatty acylation of proteins: new insights into membrane targeting of myristoylated and palmitoylated proteins. Biochim Biophys Acta (1999) 1451:1-16. doi: 10.1016/S0167-4889(99)00075-0

192. Thompson GAJr, Okuyama H. Lipid-linked proteins of plants. Prog Lipid Res. (2000) 39:19-39. doi: 10.1016/S0163-7827(99)00014-4

193. Jones DT, Cozzetto D. DISOPRED3: precise disordered region predictions with annotated protein-binding activity. Bioinformatics. (2015) 31:857-63. doi: 10.1093/bioinformatics/btu744

194. Ward JJ, Sodhi JS, McGuffin LJ, Buxton BF, Jones DT. Prediction and functional analysis of native disorder in proteins from the three kingdoms of life. J Mol Biol. (2004) 337:635-45. doi: 10.1016/j.jmb.2004.02.002
195. Dyson HJ, Wright PE. Intrinsically unstructured proteins and their functions. Nat Rev Mol Cell Biol. (2005) 6:197-208. doi: 10.1038/nrm1589

196. Søberg K, Jahnsen T, Rognes T, Skålhegg BS, Laerdahl JK. Evolutionary paths of the cAMP-dependent protein kinase (PKA) catalytic subunits. PLoS ONE (2013) 8:e60935. doi: 10.1371/journal.pone.00 60935

197. Taylor SS, Keshwani MM, Steichen JM, Kornev AP. Evolution of the eukaryotic protein kinases as dynamic molecular switches. Philos Trans $R$ Soc Lond B Biol Sci. (2012) 367:2517-28. doi: 10.1098/rstb.2012.0054

198. Canaves JM, Taylor SS. Classification and phylogenetic analysis of the cAMPdependent protein kinase regulatory subunit family. J Mol Evol. (2002) 54:17-29. doi: 10.1007/s00239-001-0013-1

199. Peng M, Aye TT, Snel B, van BB, Scholten A, Heck AJ. Spatial organization in protein kinase A signaling emerged at the base of animal evolution. J Proteome Res. (2015) 14:2976-87. doi: 10.1021/acs.jproteome.5b 00370

200. Amieux PS, McKnight GS. The essential role of RI alpha in the maintenance of regulated PKA activity. Ann N Y Acad Sci. (2002) 968:75-95. doi: 10.1111/j.1749-6632.2002.tb04328.x

201. Burton KA, McDermott DA, Wilkes D, Poulsen MN, Nolan MA, Goldstein $\mathrm{M}$, et al. Haploinsufficiency at the protein kinase A RI alpha gene locus leads to fertility defects in male mice and men. Mol Endocrinol. (2006) 20:2504-13. doi: 10.1210/me.2006-0060

202. Forlino A, Vetro A, Garavelli L, Ciccone R, London E, Stratakis CA, et al. PRKACB and Carney complex. N Engl J Med. (2014) 370:1065-7. doi: 10.1056/NEJMc1309730

203. Cheung J, Ginter C, Cassidy M, Franklin MC, Rudolph MJ, Robine N, et al. Structural insights into mis-regulation of protein kinase A in human tumors. Proc Natl Acad Sci USA. (2015) 112:1374-9. doi: 10.1073/pnas.1424206112

204. Cao Y, He M, Gao Z, Peng Y, Li Y, Li L, et al. Activating hotspot L205R mutation in PRKACA and adrenal Cushing's syndrome. Science (2014) 344:913-7. doi: 10.1126/science.1249480

205. Beuschlein F, Fassnacht M, Assie G, Calebiro D, Stratakis CA, Osswald A, et al. Constitutive activation of PKA catalytic subunit in adrenal Cushing's syndrome. N Engl J Med. (2014) 370:1019-28. doi: 10.1056/NEJMoa13 10359

206. Honeyman JN, Simon EP, Robine N, Chiaroni-Clarke R, Darcy DG, Lim II, et al. Detection of a recurrent DNAJB1-PRKACA chimeric transcript in fibrolamellar hepatocellular carcinoma. Science (2014) 343:1010-4. doi: $10.1126 /$ science. 1249484

207. Tomasini MD, Wang Y, Karamafrooz A, Li G, Beuming T, Gao J, et al. Conformational landscape of the PRKACA-DNAJB1 chimeric kinase, the driver for fibrolamellar hepatocellular carcinoma. Sci Rep. (2018) 8:720. doi: 10.1038/s41598-017-18956-w

208. Kastenhuber ER, Lalazar G, Houlihan SL, Tschaharganeh DF, Baslan $\mathrm{T}$, Chen CC, et al. DNAJB1-PRKACA fusion kinase interacts with beta-catenin and the liver regenerative response to drive fibrolamellar hepatocellular carcinoma. Proc Natl Acad Sci USA. (2017) 114:13076-84. doi: $10.1073 /$ pnas. 1716483114

Conflict of Interest Statement: The authors declare that the research was conducted in the absence of any commercial or financial relationships that could be construed as a potential conflict of interest.

Copyright (c) 2018 Søberg and Skålhegg. This is an open-access article distributed under the terms of the Creative Commons Attribution License (CC BY). The use, distribution or reproduction in other forums is permitted, provided the original author(s) and the copyright owner(s) are credited and that the original publication in this journal is cited, in accordance with accepted academic practice. No use, distribution or reproduction is permitted which does not comply with these terms. 